\title{
La evaluación de la inteligencia emocional a través del inventario de BarOn ICE: NA, en una muestra de niños y adolescentes*
}

\author{
Nelly Ugarriza Chávez \& Liz Pajares Del Águila
}

El inventario de inteligencia emocional ICE: NA de BarOn se estandarizó en una muestra de 3.375 niños y adolescentes de 7 a 18 años de Lima metropolitana. Se determinó la estructura factorial de la forma completa y abreviada del inventario mediante un análisis de los componentes principales con una rotación Varimax tanto para la muestra total como para las submuestras según sexo y gestión. Surgieron de este análisis cuatro factores empiricos: intrapersonal, interpersonal, adaptabilidad y manejo del estrés. En el estudio se destaca la validez divergente del constructo inteligencia emocional con el de depresión.

Inteligencia emocional / consistencia interna / validez de constructo y divergente / análisis factorial exploratorio

\section{Construct validity of the BarOn Emotional Quotient Inventory: youth version}

The BarOn Emotional Inventory was standardized in a representative sample of 3.375 subjects (7-18 years old) from the urban area of Lima. The factorial structure was determined for the complete and brief version of the inventory by means of a principal component analysis with varimax rotation, including sex, age and type of school (state and private) variables. Four empirical factors were confirmed, including intrapersonal, interpersonal, adaptability and stress management as initially found by BarON (2000). Indicators of divergent validity between emotional intelligence and depression constructs were revealed.

emotional intelligence / internal consistency / construct and divergent validity / factor exploratory analysis

* Las autoras agradecen a Jorge Bazán por el apoyo brindado.

Correo electrónico: nugarriz@correo.ulima.edu.pe / Ipajares@correo.ulima.edu.pe 
Actualmente los educadores y las políticas educativas destacan la gran importancia de brindar oportunidades de enseñanza-aprendizaje que enfaticen el desarrollo de las competencias emocionales y sociales. Los esfuerzos deben estar dirigidos a satisfacer de modo efectivo las necesidades sociales y emocionales de los estudiantes, lo que puede redundar en la promoción del rendimiento académico y la responsabilidad social, disminuyendo así la posibilidad de que se involucren en comportamientos de riesgo y desadaptativos, como la violencia, los actos delictivos, el uso de sustancias psicoactivas y actividades sexuales tempranas no protegidas.

La escuela puede facilitar oportunidades para el desarrollo y práctica de conductas emocionales y sociales apropiadas, tanto dentro del ambiente escolar como fuera de él, y recibir reconocimiento por ello.

Actualmente, muchos jóvenes se envuelven en conductas que incrementan la posibilidad de tener una pobre experiencia que afecta el ajuste social, emocional y académico, lo que tendrá como consecuencia un impacto negativo en la sociedad.

Desde la perspectiva constructivista social, se enfatiza lo que aprendemos a través del desarrollo, para darle significado a nuestro contexto dependiente de la experiencia emocional que se tenga a través de la exposición al discurso emocional y narrativo y al desarrollo de nuestras capacidades cognitivas. En este sentido, un enfoque del constructivismo social de las emociones es altamente individualizado: nuestra experiencia emocional es contingente a la exposición de contextos histórico-sociales específicos, y al funcionamiento desde el desarrollo cognitivo reciente. Este último componente permite transformar nuestro contexto por el hecho de que interactuamos con él (Carpendale, 1997). Nuestra única historia social incluye la inmersión en nuestras propias creencias culturales, actitudes y presunciones, a menudo comunicadas por vía narrativa y del discurso; nuestra observación de personajes y de hechos importantes así como de los patrones del refuerzo de aquellos que son significativos para nosotros. Todos estos factores contribuyen a nuestro aprendizaje, lo que significa sentir y hacer algo por ello. El concepto que le asignamos a la experiencia emocional está saturado del contexto y depende del significado que le otorgamos, incluyendo los roles que desempeñamos por razón del género, la edad y el que le otorga la sociedad.

El punto de vista del constructivismo social sobre la competencia emocional enfatiza la activa creación de nuestra experiencia emocional que se propone, integrada con el funcionamiento de nuestro desarrollo cognitivo y experiencia social.

Saarni (1999) toma en cuenta tres temas importantes para comprender la 
esencia del desarrollo emocional: regulación de ajuste, conducta expresiva y construcción de las relaciones. Estos temas tienen un carácter interactivo, conformando una madeja multidimensional que empieza y se desenvuelve de manera progresiva desde el nacimiento hasta la adolescencia, pero el funcionamiento de esta "fábrica de inteligencia emocional" es indeterminada en su extensión y su influencia puede extenderse a través de las generaciones.

Los temas expuestos por Saarni (1999) sirven como marco de referencia para la explicación del desarrollo emocional en relación con la interacción social que propone, distinguiendo: las estrategias de ajuste, la conducta expresiva emocional y el desarrollo de las relaciones sociales.

\section{ESTRATEGIAS DE AJUSTE}

Los niños aprenden diversos modelos emocionales, es decir estrategias de ajuste deseables. En una edad relativamente temprana, de seis a siete años y con el incremento de la madurez, son capaces de brindar justificaciones más elaboradas y, de acuerdo con el contexto, utilizar distintas estrategias de afronte como también tener expectativas de cómo uno se sentirá después (Saarni, 1997).

Existe un amplio cuerpo de investigación desde la perspectiva del constructivismo social que documenta los esquemas o modelos de conocimiento de los niños sobre cómo manejar la expresión de sus emociones a través de su conducta cuando enfrenta situaciones desafiantes y lo que generalmente se ha encontrado es que los niños mayores perciben, tanto la conducta emocional expresiva genuina como también la conducta emocional simulada, como actos reguladores de la conducta.

Entre los cinco y siete años ya tienen conciencia de las emociones; por ejemplo, el que sientan vergüenza es una forma de regulación. La búsqueda de soporte de las personas que los cuidan es una estrategia de ajuste predominante, pero también hay un incremento de conductas de solución de problemas frente a una situación conflictiva. Entre los siete y los diez años la estrategia de solución de problemas es la preferida; en esta etapa se espera que el niño sea capaz de trabajar y cooperar con otros cuando se encuentra en la escuela, debiendo encauzar su energía al dominio de las habilidades cognitivas, emocionales y sociales, y sentirse orgulloso de sus éxitos. Entre los diez y los trece años se incrementa una evaluación más exacta, realista y un mayor control de las circunstancias estresantes, siendo capaz de generar múltiples soluciones y estrategias diferenciadas de afronte al estrés; debe saber quién es y llegar a identificarse con sus roles. De trece años en adelante, se percatan de los cambios emocionales, por ejemplo, el culparse por sentirse molesto, lo que facilita un insight del ajuste. Hay 
una mayor integración del carácter moral de la filosofía personal para enfrentar el estrés y las decisiones futuras; también son capaces de establecer relaciones estrechas con los demás. La intimidad consiste en encontrarse uno mismo y en identificarse con la gente.

\section{CONDUCTA EMOCIONAL EXPRESIVA}

Los estudios sobre la conducta emocional expresiva son más escasos. Entre los cinco y siete años existe un afronte emocional frío ante los pares; desde los siete hasta los diez años se aprecian normas de conducta manifiestas genuinas o disfrazadas, y se utilizan conductas expresivas para modular las relaciones dinámicas, por ejemplo, "sonreír, mientras se reprocha a un amigo". Desde los diez hasta los trece años, se distingue de manera realista la conducta emocional expresiva con respecto a los amigos cercanos y el manejo que tiene con otros, y a los trece años y más se observa una mayor habilidad en la adopción de estrategias de presentación de sí mismo para impresionar.

\section{DesarRollo de LAS RELACIONES SOCIALES}

Desde los cinco hasta los siete años, se coordinan mejor las habilidades sociales y el manejo de las propias emociones con las de los demás. Hay una temprana comprensión y acuerdo por consenso sobre los signos emocionales. Entre los siete y los diez años se com- prenden las múltiples emociones que se experimentan hacia la misma persona. De diez a trece años se produce un incremento de la habilidad social y la comprensión de los signos emocionales en armonía con los roles sociales. A los trece años y más se percatan de la reciprocidad de la comunicación de las emociones que afectan la calidad de las relaciones.

Generalmente se sostiene que la adolescencia es una etapa de cambio, de crisis y que una de las características más sobresalientes en esta fase es que el joven vive en rebeldía. En la mayoría de los casos esta rebeldía se puede interpretar como un desacuerdo respecto de lo establecido por los padres, maestros o cualquier figura de autoridad. Mayormente, el desacuerdo se manifiesta como oposición o rebeldía de no querer comunicarse, en especial con los padres, otras veces bajo formas de conducta o expresiones agresivas frente a las normas o cuestionando solo por el gusto de hacerlo, siendo difícil para ellos controlar sus emociones, lo que afecta sus interacciones, sobre todo las familiares. Es una etapa de autodescubrimiento, de clarificación de las ideas y de construcción del futuro, pero mientras esto ocurre es muy posible que se enfrente a choques, desafíos, obstáculos y confrontaciones, los que debe vencer para lograr una vida feliz y saludable.

Esta introducción de los fundamentos teóricos de la competencia emocio- 
nal permite la comprensión del aprendizaje de las habilidades en contextos sociales que se exponen a continuación y que representan las creencias de la cultura occidental sobre la experiencia emocional, y cuya generalización puede ser limitada para otras culturas. Estas habilidades son presentadas en una secuencia pero no se manifiestan en habilidades ordenadas a través del desarrollo.

Es casi seguro que hasta el final de la adolescencia uno puede observar todas las habilidades que pueden ser aplicadas efectiva y competentemente; sin embargo, de acuerdo con el significado del contexto, habrá situaciones en las que responderemos con relativa competencia emocional a pesar de nuestros esfuerzos para adaptarnos de manera efectiva.

\section{HABILIDADES DE LAS COMPETENCIAS EMOCIONALES}

En el área intrapersonal es importante la comprensión de los estados emocionales, incluyendo la posibilidad de que uno experimenta múltiples emociones, y aun a niveles más maduros, percatarnos de que, en ocasiones, uno no es consciente de sus propios sentimientos por dinámicas inconscientes o por una elección preferente.

En el área interpersonal se deben desarrollar las habilidades para discriminar las emociones de los demás, basándose en gestos y situaciones expre- sivas que tienen algún grado de consenso en la cultura en cuanto a su significado emocional. Asimismo, demostrar la capacidad para involucrarse empáticamente y sintonizar con las experiencias emocionales de los otros y la habilidad para comprender que, en ocasiones, los estados emocionales internos no corresponden con la expresión externa, tanto en uno mismo como en los demás; $\mathrm{y}$, en niveles más maduros, percatarse de que nuestra conducta emocional expresiva puede impactar en los demás y, por lo tanto, tenerla en cuenta en nuestras propias estrategias de presentación. Hay que darse cuenta de que la estructura o naturaleza de las relaciones es definida en parte tanto por el grado de emoción inmediata o expresión genuina desplegada como por el grado de reciprocidad o simetría dentro de la relación; como tal, la intimidad madura es en cierta medida definida por el acto de compartir mutua o recíprocamente de modo genuino, mientras que, en ocasiones, la relación padre-hijo puede ser interesada y, por lo tanto, menos genuina.

En el área de adaptabilidad se deben lograr habilidades en el uso del vocabulario apropiado y expresar verbalmente las emociones en términos que sean comunes en la propia cultura. En niveles más maduros se adquieren signos característicos de la cultura, que vinculan las habilidades emocionales con su rol social, así como la habilidad para adaptarse y afrontar las emociones 
aversivas o estresantes utilizando estrategias autorreguladoras, como la resistencia al estrés, la conducta evitativa, que disminuye la intensidad, o la duración temporal de tales estados emocionales.

En el área del estado de ánimo en general se trata de alcanzar la capacidad emocional de autoeficacia: la persona se percibe a sí misma del modo como realmente desea sentirse. Esto es autoeficacia emocional, significa que uno acepta sus experiencias emocionales únicas y excéntricas o culturalmente convencionales, aceptación que está ligada con las creencias del individuo acerca de lo que constituye un balance emocional deseado y, en esencia, vivir de acuerdo con las propias teorías de la emoción que están integradas a nuestro sentido moral.

Los trabajos recientes de Mayer, Caruso y Salovey (1997) y BarOn (1997a) se han focalizado en establecer las propiedades psicométricas del constructo inteligencia emocional propuesto. Su misión fue demostrar que sus baterías compuestas de test y tareas (la escala multifactorial de inteligencia MEIS) podrían reunir tres clases de criterios tradicionales de la inteligencia. El análisis factorial del MEIS reveló un enfoque general de la inteligencia emocional, un factor de comprensión y un factor del manejo de las emociones.

Otros también han operacionalizado el concepto de inteligencia emocional (BarOn, 1997a; Shutte et al., 1998) y usan el constructo como una manera de predecir las diferencias individuales para la satisfacción de la vida y de la adaptabilidad.

El inventario de BarOn intenta medir "un conjunto de habilidades no cognitivas, competencias y destrezas que influyen en nuestra habilidad para tener éxito en ajustarse a las demandas y presiones del ambiente" (BarOn, 1997a). Este inventario es el que mejor ofrece y representa los indicadores más apropiados que permiten evaluar las habilidades de las competencias emocionales antes descritas, intrapersonales, interpersonales, de adaptabilidad y el estado de ánimo general. Es nuestro propósito usarlo para examinar cómo se dan estas competencias en una muestra de niños $\mathrm{y}$ adolescentes peruanos.

Es conocido que el constructo de inteligencia emocional ha captado un interés considerable debido a su popularización en diversos libros, como el de Goleman (1996) y artículos que han aparecido en la prensa de manera tardía. En la literatura científica, sin embargo, los componentes básicos de este constructo fueron elaborados hace más de una década (BarOn, 1988; Gardner, 1983; Salovey \& Mayer, 1989-1990), con precursores desde inicios del siglo XX (BarOn \& Parker, 2000).

En las primeras contribuciones teóricas, Salovey \& Mayer (1989-1990) definieron la inteligencia emocional como "la habilidad para monitorear nuestros propios sentimientos y emo- 
ciones y la de los demás, para discriminar entre ellas y usar esta información para guiar nuestros pensamientos y acciones". Recientemente, Mayer \& Salovey (1997) propusieron una revisión de esta definición enfatizando cuatro componentes primarios de la inteligencia emocional: la percepción, evaluación y expresión de la emoción; la facilitación emocional del pensamiento; la comprensión, análisis y el empleo del conocimiento emocional; y el control de las emociones para promover el crecimiento emocional e intelectual.

La teoría formulada por Salovey \& Mayer (1990) enmarca la inteligencia emocional dentro un modelo de inteligencia, enfatizando el aspecto cognitivo para diferenciarlo de las habilidades sociales, centrándose en aptitudes mentales específicas para reconocer y ordenar las emociones.

Sugirieron que un modelo de inteligencia emocional debe incluir alguna medida "de pensar acerca de los sentimientos", una aptitud dejada de lado por otros modelos que se centran simplemente en percibir y regular los sentimientos.

Por otro lado, el modelo de Mayer, Salovey \& Caruso (2000) sostiene que la inteligencia debe cumplir con tres criterios para definirse como tal: la inteligencia debe ser conceptual, reflejar las actitudes mentales antes que los comportamientos; debe ser correlacional, es decir, compartir similitudes con otras inteligencias establecidas; y debe poder desarrollarse, es decir, las capacidades deben incrementarse de acuerdo con la experiencia y edad del individuo. Esta definición teórica sobre inteligencia emocional es la de mayor amplitud, debido a su consideración por los procesos emocionales que incluyen codificación, elaboración y producción de la información emocional, y las relaciones interpersonales e intrapersonales donde se realizan dichos procesos.

El modelo de Goleman (1988) destaca la inteligencia emocional en términos de una teoría de desarrollo. Presenta una teoría de desempeño que tiene aplicabilidad directa al dominio del trabajo y efectividad de la organización.

El concepto de la teoría de Goleman (1998) del desempeño de la inteligencia emocional comprende un grupo discreto de capacidades que integran habilidades afectivas y cognitivas, pero que son distintas de las habilidades medidas por los test tradicionales de coeficiente intelectual (CI). Así mismo, distingue entre la inteligencia emocional y las competencias emocionales, que define como "la capacidad de aprendizaje basado en la inteligencia emocional, que resulta en un desempeño sobresaliente en el trabajo".

\section{El MOdelo de INTELIGENCIA DE BARON}

De acuerdo con el modelo de BarOn (1997), la inteligencia emocional es definida como un conjunto de habilidades emocionales, personales e interpersona- 
les que influyen en nuestra habilidad general para afrontar las demandas y presiones del medio ambiente. Como tal, nuestra inteligencia emocional es un factor importante en la determinación de nuestra habilidad para tener éxito en la vida. Directamente influye en nuestro bienestar emocional general. Según este modelo:

Las personas emocionalmente inteligentes son capaces de reconocer y expresar sus emociones, comprenderse a sí mismos, actualizar sus capacidades potenciales, llevar una vida regularmente saludable y feliz. Son capaces de comprender la manera como las otras personas se sienten, de tener y mantener relaciones interpersonales satisfactorias y responsables, sin llegar a ser dependientes de los demás. Son generalmente optimistas, flexibles, realistas, tienen éxito en resolver sus problemas y afrontar el estrés, sin perder el control (BarOn, 1997a).

Así, de acuerdo con el modelo de BarOn, la inteligencia general está compuesta tanto por la inteligencia cognitiva, evaluada por el CI, como por la inteligencia emocional, evaluada por el $\mathrm{CE}$ (coeficiente emocional). Las personas saludables que funcionan bien y son exitosas poseen un grado suficiente de inteligencia emocional. La inteligencia emocional se desarrolla a través del tiempo, cambia a través de la vida, y puede ser mejorada con entrenamiento y programas remediales como también por intervenciones terapéuticas.

La inteligencia emocional se combina con otros determinantes importantes de nuestra habilidad para tener éxito en adaptarse a las demandas del medio ambiente, tales como las características básicas de la personalidad y la capacidad intelectual cognitiva.

El modelo de BarOn es multifactorial y se relaciona con el potencial para el rendimiento, antes que con el rendimiento en sí mismo (por ejemplo, el potencial para tener éxito antes que con el éxito en sí mismo) es un modelo orientado en el proceso antes que un modelo orientado hacia los logros.

Asimismo, el modelo de BarOn (1988) comprende cinco componentes principales: intrapersonal, interpersonal, adaptabilidad, manejo del estrés y estado de ánimo general. A su vez, cada una de estas amplias dimensiones involucra un número de subcomponentes que son habilidades relacionadas, que han sido descritas y analizadas en el estudio de la inteligencia emocional de los adultos (Ugarriza, 2003).

Un modelo relacionado fue empíricamente desarrollado por BarOn $(1988,1997 a)$ y corroborado por Ugarriza (2003) por medio del análisis factorial confirmatorio de segundo orden; este modelo es particularmente interesante porque forma la base teórica del inventario de cociente emocional de BarOn (EQ-i; BarOn, 1997a), que es la medición de la inteligencia emocional más ampliamente utilizada en adultos, que ha servido de base para el desarrollo del BarOn ICE: NA. 
La evaluación de la inteligencia emocional en niños y adolescentes comprende cinco escalas:

- Escala intrapersonal.- Incluye la medición de la autocomprensión de sí mismo, la habilidad para ser asertivo y la habilidad para visualizarse a sí mismo de manera positiva.

- Escala interpersonal.- Incluye destrezas como la empatía y la responsabilidad social, el mantenimiento de relaciones interpersonales satisfactorias, el saber escuchar y ser capaces de comprender y apreciar los sentimientos de los demás.

- Escala de adaptabilidad.- Incluye la habilidad para resolver los problemas y la prueba de la realidad, ser flexibles, realistas y efectivos en el manejo de los cambios y ser eficaces para enfrentar los problemas cotidianos.

- Escala de manejo del estrés.- Incluye la tolerancia al estrés y el control de los impulsos, ser por lo general calmado y trabajar bien bajo presión, ser rara vez impulsivo y responder a eventos estresantes sin desmoronarse emocionalmente.

- Escala de estado de ánimo general.Incluye la felicidad y el optimismo, tienen una apreciación positiva sobre las cosas o eventos y es particularmente placentero estar con ellos. Una visión más actualizada del inventario indica que el estado de ánimo general opera como un facilita- dor de la inteligencia emocional antes de formar una parte de él.

Además, el inventario proporciona un cociente emocional total que expresa cómo se afrontan en general las demandas diarias, así como una escala de impresión positiva que evalúa la percepción excesivamente favorable de sí mismo y un índice de inconsistencia que expresa la discrepancia de las respuestas a similares.

\section{Objetivos}

- Adaptar y estandarizar el inventario del cociente emocional en una muestra representativa de niños y adolescentes de la ciudad de Lima.

- Describir los efectos aislados y combinados del sexo, la edad y el tipo de gestión sobre las habilidades emocionales y sociales.

- Establecer la confiabilidad y la validez de constructo del inventario.

- Desarrollar normas de aplicación, calificación e interpretación de los resultados.

\section{MUESTREO}

Se tomó una muestra de 3.374 evaluados; inicialmente fueron 3.539 pero se eliminaron los cuestionarios respondidos por los niños de primer grado y los de aquellos que habían omitido el sexo y la edad.

El método de muestreo empleado fue el no probabilístico de tipo intencional, según los siguientes criterios: 
- Criterios de inclusión

- Edades comprendidas entre los 7 y $\operatorname{los} 18$ años.

- Criterios de exclusión

- Más de 6 omisiones en la versión larga de la prueba.

- Índice de inconsistencia mayor de 10 .

El objetivo era representar la población de niños y adolescentes de Lima metropolitana según su distribución porcentual de edades. Para lograr la representatividad se tomó como referencia la distribución porcentual por edades de Lima metropolitana, dada en la matrícula escolar Encuesta Nacional de Hogares (Enaho, INEI, 1999). Se optó por el uso de un sistema de ponderación al no garantizarse en la muestra inicial ni en la depurada, las proporciones esperadas según los grupos de edad considerados. Estos aspectos se detallan a continuación.

Tabla 1

Distribución de la muestra inicial según sexo y grupos de edad

\begin{tabular}{lrrrr}
\hline $\begin{array}{l}\text { Grupos } \\
\text { de edad }\end{array}$ & Masc. & Fem. & \multicolumn{1}{c}{ Total } & $\%$ \\
\hline 7 a 9 años & 479 & 470 & 949 & 26,8 \\
10 a 12 años & 629 & 558 & 1.187 & 33,6 \\
13 a 15 años & 577 & 446 & 1.023 & 28,9 \\
16 a 18 años & 191 & 189 & 380 & 10,7 \\
\hline Total & 1.876 & 1.663 & 3.539 & 100,0 \\
\hline
\end{tabular}

\section{Muestra inicial}

La tabla 1 presenta la distribución de la muestra obtenida según sexo y grupos de edad. En esta muestra no se consideran los protocolos que fueron eliminados por omisión de respuestas a las preguntas de BarOn ICE: NA.

\section{Muestra final}

Se examinó la validez de los 3.539 protocolos de la muestra inicialmente seleccionada que no presentaban omisión. En esta evaluación los criterios de exclusión se consideraron en el siguiente orden: los protocolos con más de seis omisiones y el índice de inconsistencia por encima de 10.

Como consecuencia de esta evaluación se excluyeron 165 protocolos, obteniéndose una muestra definitiva de 3.374 evaluados, como se indica en la tabla 2.

Tabla 2

Distribución de la muestra final según sexo y grupos de edad

\begin{tabular}{lrrrr}
\hline $\begin{array}{l}\text { Grupos } \\
\text { de edad }\end{array}$ & Masc. & Fem. & \multicolumn{1}{c}{ Total } & \multicolumn{1}{c}{$\%$} \\
\hline 7 a 9 años & 448 & 429 & 877 & 26,0 \\
10 a 12 años & 618 & 536 & 1.154 & 34,2 \\
13 a 15 años & 557 & 435 & 992 & 29,4 \\
16 a 18 años & 179 & 172 & 351 & 10,4 \\
\hline Total & 1.082 & 1.572 & 3.374 & 100,0 \\
\hline
\end{tabular}




\section{Muestra ponderada}

Al observar la distribución de los porcentajes de evaluados dentro de los grupos de edad considerados, se comprobó que no se corresponden con la distribución porcentual de la Enaho (INEI, 1999). Como consecuencia de esto se hizo necesario emplear un sistema de ponderación que restituya la proporcionalidad de los grupos de edad considerados en el ámbito de Lima metropolitana.

La variable de ponderación fue 1.25 para las edades de 7 a 9 años, pues se encontraban subrepresentadas, y de $0.91,0.88$, y 1.01 para los siguientes grupos de edad. La tabla 3 muestra la distribución de evaluados por edad y sexo luego del uso de la ponderación.

El sistema de ponderación permite obtener un baremo apropiado para la muestra completa, pues restituye las verdaderas proporciones de los grupos de edad.

Hay que notar que los baremos que puedan obtenerse por separado para varones y mujeres están plenamente justificados debido al tamaño de la muestra, no así en el caso que se desee tener baremos para varones y mujeres en todos los grupos de edad.

El $46,8 \%$ de la muestra está constituida por mujeres y el $53,2 \%$ son varones. Los alumnos fueron evaluados en sus respectivas instituciones escolares. La distribución de la muestra por grado y gestión educativa se puede observar en la tabla 4.

Tabla 3

Distribución de la muestra final ponderada por sexo y grupos de edad ${ }^{1}$

\begin{tabular}{lcccc}
\hline $\begin{array}{l}\text { Grupos } \\
\text { de edad }\end{array}$ & Masc. & Fem. & \multicolumn{1}{c}{ Total } & \multicolumn{1}{c}{$\%$} \\
\hline 7 a 9 años & 561 & 537 & 1.098 & 32,53 \\
10 a 12 años & 564 & 489 & 1.053 & 31,20 \\
13 a 15 años & 488 & 381 & 869 & 25,75 \\
16 a 18 años & 181 & 174 & 355 & 10,52 \\
\hline Total & 1.794 & 1.581 & 3.375 & 100,00
\end{tabular}

1 Ponderada basándose en la distribución de edades en la Enaho (INEI, 1999).

Tabla 4

Distribución de la muestra según grado y gestión

\begin{tabular}{lccc}
\hline Grados & Estatal & Particular & Total \\
\hline 2. primaria & 100 & 250 & 350 \\
3. primaria & 177 & 250 & 427 \\
4. primaria & 235 & 227 & 462 \\
5. primaria & 142 & 185 & 327 \\
6. primaria & 316 & 183 & 499 \\
1. secundaria & 288 & 127 & 415 \\
2. secundaria & 165 & 53 & 218 \\
3. secundaria & 133 & 121 & 254 \\
4. secundaria & 210 & 50 & 260 \\
5. secundaria & 91 & 71 & 162 \\
\hline Total & 1.857 & 1.517 & 3.374 \\
\hline
\end{tabular}




\section{Descripción del instrumento}

\section{Ficha técnica}

Nombre original

Autor

Procedencia

Adaptación peruana Administración

Formas

Duración

Aplicación

Puntuación

Significación

Tipificación

Usos

Materiales
: EQi-YV BarOn Emotional Quotient Inventory

: Reuven BarOn

: Toronto, Canadá

: Nelly Ugarriza Chávez y Liz Pajares Del Aguila

: Individual o colectiva.

: Formas completa y abreviada

: Sin límite de tiempo (forma completa: 20 a 25 minutos, aproximadamente y abreviada de 10 a 15 minutos).

: Niños y adolescentes entre 7 y 18 años.

: Calificación computarizada

: Evaluación de las habilidades emocionales y sociales.

: Baremos peruanos

: Educacional, clínico, jurídico, médico y en la investigación. Son usuarios potenciales los profesionales que se desempeñan como psicólogos, psiquiatras, médicos, trabajadores sociales, consejeros, tutores y orientadores vocacionales.

: Un disquete que contiene cuestionarios de las formas completa y abreviada, calificación computarizada y perfiles presentados en el Manual técnico del ICE: NA (Ugarriza y Pajares, 2004).
CARACTERÍSTICAS PRINCIPALES DEL

\section{BARON ICE: NA}

El BarOn ICE: NA es un inventario que integra conocimientos teóricos, fundamentos empíricos y una fina sofistificación de las técnicas psicométricas. El instrumento es confiable, válido y ofrece al usuario un número importante de características que incluyen:
- Una muestra normativa amplia $(\mathrm{N}=$ 3.374).

- Normas especificas de sexo y edad (cuatro diferentes grupos de edades entre los 7 y 18 años).

- Escalas multidimensionales que evalúan las características centrales de la inteligencia emocional. 
- Una escala de impresión positiva para identificar a los que intentan crear una imagen exageradamente favorable de sí misma.

- Un factor de corrección que permite al usuario un ajuste de las respuestas positivas que tienden a dar los niños muy pequeños.

- Un índice de inconsistencia diseñado para detectar el estilo de respuesta discrepante.

- Pautas para la administración, calificación y obtención de un perfil de resultados computarizado.

- Alta confiabilidad y validez.

El BarOn ICE: NA contiene 60 ítems distribuidos en 7 escalas. También incluye una escala que evalúa las respuestas inconsistentes.

En el anexo se presentan las formas completa y abreviada del BarOn ICE: NA que contienen 60 y 30 ítems, respectivamente. La información es aplicable a ambas formas de inventario. Las tablas 5 y 6 muestran las escalas del ICE: NA de BarOn para ambas formas.

El ICE BarOn: NA usa una escala de tipo Likert de cuatro puntos, en la cual los evaluados responden a cada ítem según las siguientes opciones de respuestas: "muy rara vez", "rara vez", "a menudo" y "muy a menudo". Los puntajes altos del inventario indican niveles elevados de inteligencia emocional y social.
Tabla 5

Mediciones contenidas en el ICE: NA - Forma completa

Inteligencia emocional total Interpersonal Intrapersonal

Adaptabilidad

Manejo del estrés

Estado de ánimo general Impresión positiva

Índice de inconsistencia

Tabla 6

Mediciones contenidas en el

ICE: NA - Forma abreviada

Inteligencia emocional total Interpersonal Intrapersonal Adaptabilidad

Impresión positiva

\section{DesarRollo del INVENTARIO de BARON EQ-I}

\section{Desarrollo de la escala preliminar}

En Estados Unidos el proceso de desarrollo del inventario se inició con un pequeño grupo de expertos en el área de evaluación de niños y adolescentes, quienes examinaron si los 133 ítems del inventario del ICE BarOn para adultos (1997a) eran apropiados para usarlos en edades comprendidas entre $\operatorname{los} 7$ y 18 años. Con las recomendaciones de estos expertos, aproximadamente el 25 por ciento de los ítems del inventario fueron retenidos para una ver- 
sión piloto del instrumento para adolescentes, y el 25 por ciento de los restantes fueron abreviados o modificados para que sean más apropiados con los niños menores. Los autores escribieron un nuevo conjunto de ítems y añadieron otros, produciendo un total de 96 reactivos.

\section{Análisis exploratorio de la escala}

Se utilizó una muestra de 371 niños y adolescentes (160 varones y 211 mujeres) con las edades comprendidas entre 7 y 18 años. El promedio de edad para la muestra fue de 13.44 años (D.E. = 2.85). Participaron voluntarios de diferentes escuelas de Canadá y Estados Unidos, los que respondieron a los 96 ítems de la versión preliminar del instrumento. Se halló un modelo de cuatro factores como la mejor estructura para el conjunto de ítems usando el análisis factorial exploratorio con rotación Varimax. Este modelo (que usó 30 ítems) era virtualmente idéntico en los menores de 12 años y mayores de 13 años. Además, era semejante a los cuatro componentes del ICE para adultos: intrapersonal, interpersonal, adaptabilidad y manejo del estrés. Una serie de análisis exploratorios con un conjunto de ítems sobre felicidad y optimismo agrupó 12 para el factor "estado de ánimo general". Otra serie separada de análisis factorial exploratorio con un conjunto de ítems de impresión positiva dio origen a un factor de "impresión positiva" de seis ítems. Sobre la base de estos análisis factoriales exploratorios, 48 ítems del conjunto original fueron retenidos para el desarrollo de las siguientes fases.

\section{Reestructuración de la escala}

Durante esta etapa los autores escribieron un nuevo conjunto de 33 ítems que cubrían una sección transversal de la inteligencia emocional, principalmente en la que se basó el modelo de BarOn. Estos fueron añadidos al conjunto de 48 ítems (identificados durante la fase 2) para producir un instrumento revisado de 81 ítems.

\section{Análisis factorial exploratorio de los 81 ítems de la escala}

Se trabajó con una muestra de 800 niños y adolescentes de Canadá y Estados Unidos con edades entre 7 y 18 años (354 varones y 428 mujeres; 18 de ellos no señalaron el sexo), los que completaron los 80 ítems de la versión preliminar del instrumento. La media de edad para la muestra fue de 13.26 años (D.S. = 3.56).

Usando un análisis factorial exploratorio con una rotación Varimax se halló un modelo de cuatro factores para los ítems del área intrapersonal, interpersonal, adaptabilidad y manejo del estrés, siendo este la mejor estructura. El modelo, que utilizó 40 ítems de un conjunto de 81 , fue muy similar a la di- 
mensión de cuatro componentes medidos por el inventario de adultos (intrapersonal, interpersonal, adaptabilidad y manejo del estrés). Una serie de análisis factoriales con los ítems de estado de ánimo reunió 14, denominado "Factor de estado de ánimo general". Se ejecutó otro análisis factorial con los ítems de impresión positiva, conformándose un factor con seis ítems. Basado en este conjunto de análisis factoriales, 60 ítems fueron retenidos para el desarrollo de la escala final de BarOn ICE: NA.

\section{Análisis factorial confirmatorio del BarOn ICE: NA}

Se utilizó una muestra de 280 niños y adolescentes entre 6 y 18 años, 133 varones y 147 mujeres. La media de edad para esta muestra fue de 12.53 y la D.E. de 2.76. Se corroboró empíricamente el modelo de cuatro factores con el análisis factorial confirmatorio. Lo mismo ocurrió con el factor de la escala de estado de ánimo general y el factor de la escala de impresión positiva. Con base en los análisis de las fases previas, la versión final del BarOn ICE: NA contiene 60 ítems.

\section{Creación del índice de inconsistencia}

El índice de inconsistencia es una de las mediciones de la validez del BarOn ICE: NA que fue diseñada para evaluar la consistencia. Las respuestas altamen- te inconsistentes pueden ser producidas por falta de motivación o disposición de los evaluados para participar, lo que puede comprometer la validez de los resultados. El BarOn ICE: NA contiene varios pares de ítems altamente correlacionados que tienen un contenido similar, que pueden ser utilizados para verificar respuestas inconsistentes. Los 10 pares de ítems del BarOn ICE: NA fueron utilizados para este índice.

El puntaje del índice de inconsistencia es computado calculando las diferencias de valores absolutos en cada par de respuestas y luego sumando estas 10 diferencias. Algún grado de respuesta inconsistente es natural y esperado. Para niños y adolescentes (de cualquier edad) un puntaje de 10 o mayor debe ser tratado como atípico en términos de respuestas consistentes.

Las puntuaciones bajas en el índice de inconsistencia no garantiza que los resultados sean válidos. Una persona que responde completamente al azar al BarON ICE: NA posiblemente podría obtener un puntaje bajo en este índice. También puede significar que el probando tiene dificultades en comprender las diferencias sutiles entre algunos ítems. Los puntajes elevados en este índice también pueden indicar una autocomprensión pobremente desarrollada. De allí que se recomienda a los usuarios de la prueba que tengan información adicional sobre la conducta del evaluado, lo que ayudará a determinar la validez de los resultados. 
Creación de la forma abreviada del BarOn ICE: NA

La forma abreviada fue desarrollada para usarla cuando se administran diversos instrumentos, para aquellos examinados que se fatigan fácilmente, en los casos con dificultades lectoras o con una comprensión limitada, y también para minimizar el tiempo de aplicación. Se usó una muestra normativa de 9.172 sujetos. El objetivo fue desarrollar una escala que incluyera suficientes ítems (6 por escala) para evaluar de modo confiable las habilidades intrapersonal, interpersonal, de adaptabilidad y de manejo del estrés. La suma de estas escalas abreviadas constituye el CE total de la escala. Esta forma también incluye los mismos seis ítems de la Escala de impresión positiva que aparece en la forma completa. Así, el BarOn ICE: NA en su forma abreviada contiene 30 ítems. Los seis ítems de la escala intrapersonal de la escala completa fueron retenidos para la forma abreviada.

Para las escalas intrapersonal, interpersonal, adaptabilidad y manejo del estrés, de la forma completa, el pool de ítems para cada escala fue sujeto a un análisis factorial confirmatorio con el programa Statística (StafSoft, 1995) probando un modelo unidimensional. Para crear las versiones de los seis ítems de cada escala solo se utilizaron los seis ítems con las cargas factoriales más altas.

\section{Desarrollo del inventario de BarOn ICE: NA en la muestra peruana}

En la adaptación y estandarización peruana que tuvo lugar en Lima en el año 2002, se procedió en primer término a la traducción del inventario del inglés al castellano; participaron seis psicólogos peruanos con dominio del inglés y se examinó la concordancia entre las diferentes versiones, seleccionándose aquellos reactivos que por su contenido expresaban las definiciones operacionales del constructo. Luego, esta versión fue examinada por una traductora norteamericana con dominio del castellano confirmándose la equivalencia lingüística y el significado de los diferentes ítems.

Así mismo, la versión preliminar fue aplicada en niños de 7 a 10 años para asegurar el nivel de comprensión de cada reactivo. De esta manera, se obtuvo la versión final del instrumento que se aplicó a la muestra de estandarización.

Para la determinación de los índices de inconsistencia se siguió el mismo proceso de la versión norteamericana. Los resultados se presentan en la tabla 7 , donde se observa que las correlaciones entre los ítems pares similares son significativas al uno por ciento, lo que coincide con los resultados americanos aun cuando las correlaciones obtenidas en la muestra peruana son más bajas; esto se debe a factores motivacionales o a que algunos niños más pequeños tenían un bajo nivel de comprensión lectora (7 a 10 años), lo que fue considerado para el ajuste del puntaje total. 
Tabla 7

Inventario emocional

\begin{tabular}{|c|c|c|}
\hline Ítem No & Contenido de los ítems & Correlación \\
\hline 17 & Puedo hablar fácilmente sobre mis sentimientos & \\
\hline 43 & Para mí es fácil decirle a las personas cómo me siento & $r=+.37^{* *}$ \\
\hline 7 & Es fácil decirle a la gente cómo me siento & \\
\hline 31 & Puedo fácilmente describir mis sentimientos & $r=+.25^{\star *}$ \\
\hline 55 & Puedo darme cuenta cuando mi amigo se siente triste & \\
\hline 59 & Sé cuándo la gente está molesta aun cuando no dice nada & $r=+.32^{* *}$ \\
\hline 20 & Tener amigos es importante & \\
\hline 51 & Me agradan mis amigos & $r=+.27^{* *}$ \\
\hline 30 & Puedo dar buenas respuestas a preguntas difíciles & \\
\hline 22 & Puedo comprender preguntas difíciles & $r=+.40^{* *}$ \\
\hline 38 & Puedo usar fácilmente diversos modos de resolver problemas & \\
\hline 48 & Soy bueno resolviendo problemas & $r=+.35^{\star *}$ \\
\hline 26 & Tengo mal genio & \\
\hline 35 & Me molesto fácilmente & $r=+.34^{* *}$ \\
\hline 3 & Puedo mantener la calma cuando estoy molesto & \\
\hline 11 & Sé cómo mantenerme tranquilo & $r=+.21$ \\
\hline 40 & Me siento bien conmigo mismo & \\
\hline 47 & Me siento feliz con la clase de persona que soy & $r=+.36^{* *}$ \\
\hline 56 & Me gusta mi cuerpo & \\
\hline 60 & Me gusta la forma como me veo & $r=+.48^{\star *}$ \\
\hline
\end{tabular}

\section{Resultados}

\section{Datos normativos peruanos}

En las tablas 8 a 11 se presentan las medias, las desviaciones estándares, las diferencias de medias y niveles de significación para las distintas escalas del BarOn ICE: NA para las formas completa y abreviada. Estas estadísticas se presentan por separado considerando el sexo y la gestión para los cuatro grupos de edades: 7 a 9 años, 10 a 12 años, 13 a 15 años y 16 a 18 años.

En las tablas 12 a 15 se muestran las medias y desviaciones estándar obtenidas mediante el análisis de covarianza para las diferentes escalas. Esta estadís- tica ha sido empleada para obtener los perfiles y puntajes estándar que han sido desarrollados a través de un programa computarizado para ambas formas de la prueba, para todos los posibles puntajes directos y las diferentes escalas, considerando por separado las variables sexoedad. Estas medias han sido ajustadas mediante el análisis Ancova, utilizando como covariable la escala de impresión positiva para evitar, en lo posible, la influencia de sesgos referidos a las respuestas de deseabilidad social. De este modo los puntajes de escala son presentados como una representación más exacta de la respuesta emocional del evaluado en el BarOn ICE: NA. 
Tabla 8

Medias, desviaciones estándares y prueba t de Student de las escalas del Inventario BarOn: NA - Forma completa por grupos de edad y sexo

\begin{tabular}{|c|c|c|c|c|c|}
\hline \multirow[t]{2}{*}{$\begin{array}{c}\text { Grupo de edad } \\
\text { Escalas del BarOn ICE: NA }\end{array}$} & \multicolumn{2}{|c|}{ Varón } & \multicolumn{2}{|c|}{ Mujer } & \multirow[b]{2}{*}{$\mathrm{t}$} \\
\hline & $\mathrm{M}$ & $\mathrm{DE}$ & M & $\mathrm{DE}$ & \\
\hline \multicolumn{6}{|c|}{7 a 9 años $(\mathrm{N}=561$ para varones; $\mathrm{N}=537$ para mujeres $)$} \\
\hline Intrapersonal & 14.85 & 3.33 & 14.42 & 3.35 & 2.13 \\
\hline Interpersonal & 37.09 & 6.24 & 37.99 & 6.02 & -2.42 \\
\hline Adaptabilidad & 30.23 & 5.88 & 29.04 & 5.62 & $3.41^{* * *}$ \\
\hline Manejo del estrés & 32.89 & 6.24 & 33.50 & 6.29 & -1.62 \\
\hline Total cociente emocional & 56.64 & 7.01 & 56.33 & 6.54 & .76 \\
\hline Estado de ánimo en general & 46.51 & 6.65 & 46.96 & 6.30 & -1.62 \\
\hline Impresión positiva & 17.04 & 3.16 & 16.49 & 3.01 & $2.92^{* *}$ \\
\hline \multicolumn{6}{|c|}{10 a 12 años $(\mathrm{N}=564$ para varones; $\mathrm{N}=489$ para mujeres $)$} \\
\hline Intrapersonal & 14.17 & 3.20 & 13.88 & 3.32 & 1.41 \\
\hline Interpersonal & 36.42 & 5.71 & 38.43 & 5.39 & $-5.85^{\star * *}$ \\
\hline Adaptabilidad & 29.15 & 5.14 & 28.67 & 4.86 & 1.57 \\
\hline Manejo del estrés & 33.57 & 5.55 & 33.37 & 5.94 & .57 \\
\hline Total cociente emocional & 55.55 & 6.47 & 55.82 & 6.51 & -.68 \\
\hline Estado de ánimo en general & 46.07 & 6.76 & 45.49 & 6.57 & .14 \\
\hline Impresión positiva & 15.97 & 5.93 & 15.73 & 2.76 & 1.35 \\
\hline \multicolumn{6}{|c|}{13 a 15 años ( $N=487$ para varones; 381 para mujeres) } \\
\hline Intrapersonal & 14.33 & 3.05 & 14.35 & 3.19 & -.70 \\
\hline Interpersonal & 35.13 & 5.47 & 37.36 & 5.58 & $-5.88^{* * *}$ \\
\hline Adaptabilidad & 28.03 & 5.03 & 27.50 & 5.14 & 1.52 \\
\hline Manejo del estrés & 33.86 & 5.38 & 33.51 & 5.61 & .943 \\
\hline Total cociente emocional & 54.71 & 6.17 & 55.23 & 6.62 & -1.21 \\
\hline Estado de ánimo en general & 44.43 & 6.40 & 43.29 & 7.11 & $2.48^{*}$ \\
\hline Impresión positiva & 15.34 & 2.71 & 15.02 & 2.81 & 1.71 \\
\hline \multicolumn{6}{|c|}{16 a 18 años ( $\mathrm{N}=181$ para varones; 174 para mujeres $)$} \\
\hline Intrapersonal & 14.65 & 3.31 & 14.16 & 3.51 & 1.35 \\
\hline Interpersonal & 34.35 & 5.31 & 37.58 & 5.40 & $-5.68^{\star *}$ \\
\hline Adaptabilidad & 27.17 & 4.65 & 27.90 & 5.22 & -1.40 \\
\hline Manejo del estrés & 33.38 & 5.19 & 32.01 & 5.37 & $2.45^{*}$ \\
\hline Total cociente emocional & 54.01 & 6.50 & 54.74 & 6.43 & -1.06 \\
\hline Estado de ánimo en general & 42.14 & 6.58 & 41.91 & 7.31 & .31 \\
\hline Impresión positiva & 14.92 & 2.65 & 14.96 & 2.84 & -.15 \\
\hline
\end{tabular}

p. $<.001^{* * *}$ p. $<.01^{* *}$ p. $<.05^{*}$

Tabla 9

Medias, desviaciones estándar y prueba t de Student de las escalas del Inventario BarOn: NA - Forma abreviada por grupos de edad y sexo

\begin{tabular}{|c|c|c|c|c|c|}
\hline \multirow[t]{2}{*}{$\begin{array}{c}\text { Grupo de edad } \\
\text { Escalas del BarOn ICE: NA }\end{array}$} & \multicolumn{2}{|c|}{ Varón } & \multicolumn{2}{|c|}{ Mujer } & \multirow[b]{2}{*}{$\mathrm{t}$} \\
\hline & $\mathrm{M}$ & $\mathrm{DE}$ & M & $\mathrm{DE}$ & \\
\hline \multicolumn{6}{|c|}{7 a 9 años ( $\mathrm{N}=561$ para varones; $\mathrm{N}=537$ para mujeres $)$} \\
\hline Intrapersonal & 14.85 & 3.33 & 14.42 & 3.35 & $2.13^{*}$ \\
\hline Interpersonal & 18.81 & 3.71 & 19.57 & 3.34 & $-3.55^{\star * *}$ \\
\hline Adaptabilidad & 18.07 & 4.01 & 17.36 & 3.83 & $3.03^{* *}$ \\
\hline Manejo del estrés & 17.08 & 4.28 & 17.71 & 4.32 & $-2.45^{*}$ \\
\hline Total cociente emocional & 68.82 & 9.18 & 69.07 & 8.48 & -.46 \\
\hline Impresión positiva & 17.04 & 3.16 & 16.49 & 3.01 & $2.92^{* *}$ \\
\hline \multicolumn{6}{|c|}{10 a 12 años $(\mathrm{N}=564$ para varones; $\mathrm{N}=489$ para mujeres $)$} \\
\hline Intrapersonal & 14.17 & 3.20 & 13.88 & 3.32 & 1.41 \\
\hline Interpersonal & 18.26 & 3.26 & 19.47 & 3.15 & $-6.13^{\star * *}$ \\
\hline Adaptabilidad & 17.51 & 3.61 & 17.03 & 3.38 & $2.21^{*}$ \\
\hline Manejo del estrés & 17.54 & 3.70 & 17.50 & 3.92 & .17 \\
\hline Total cociente emocional & 67.47 & 8.57 & 67.88 & 8.66 & -.78 \\
\hline Impresión positiva & 15.97 & 2.93 & 15.73 & 2.76 & 1.36 \\
\hline \multicolumn{6}{|c|}{13 a 15 años ( $\mathrm{N}=487$ para varones; 381 para mujeres $)$} \\
\hline Intrapersonal & 14.33 & 3.05 & 14.35 & 3.19 & -.070 \\
\hline Interpersonal & 17.41 & 3.07 & 18.96 & 3.08 & $-7.35^{\star \star *}$ \\
\hline Adaptabilidad & 16.67 & 3.38 & 16.19 & 3.49 & $2.04^{*}$ \\
\hline Manejo del estrés & 17.74 & 3.59 & 17.66 & 3.71 & .32 \\
\hline Total cociente emocional & 66.15 & 7.73 & 67.16 & 8.09 & -1.86 \\
\hline Impresión positiva & 15.34 & 2.71 & 15.02 & 2.81 & 1.71 \\
\hline \multicolumn{6}{|c|}{16 a 18 años ( $\mathrm{N}=181$ para varones; 174 para mujeres $)$} \\
\hline Intrapersonal & 14.65 & 3.31 & 14.16 & 3.51 & 1.35 \\
\hline Interpersonal & 17.11 & 3.08 & 19.35 & 2.94 & $-7.03^{* * *}$ \\
\hline Adaptabilidad & 16.12 & 3.24 & 16.31 & 3.65 & -.51 \\
\hline Manejo del estrés & 17.44 & 3.22 & 16.54 & 3.72 & $2.44^{*}$ \\
\hline Total cociente emocional & 65.32 & 8.54 & 66.36 & 8.09 & -1.18 \\
\hline Impresión positiva & 14.92 & 2.65 & 14.96 & 2.84 & -.15 \\
\hline
\end{tabular}

p. $.001^{* * *}$ p. $.01^{* *}$ p. $.05^{*}$ 
Tabla 10

Medias, desviaciones estándar y prueba t de Student de las escalas del Inventario BarOn: NA - Forma completa por grupos de edad y gestión

\begin{tabular}{|c|c|c|c|c|c|}
\hline \multirow[t]{2}{*}{$\begin{array}{c}\text { Grupo de edad } \\
\text { Escalas del BarOn ICE: NA }\end{array}$} & \multicolumn{2}{|c|}{ Estatal } & \multicolumn{2}{|c|}{ Particular } & \multirow[b]{2}{*}{$\mathrm{t}$} \\
\hline & M & $\mathrm{DE}$ & M & $\mathrm{DE}$ & \\
\hline \multicolumn{6}{|c|}{7 a 9 años ( $\mathrm{N}=466$ para estatal; $\mathrm{N}=632$ para particular) } \\
\hline Intrapersonal & 14.01 & 3.32 & 15.11 & 3.28 & $-5.46^{* * *}$ \\
\hline Interpersonal & 34.42 & 5.87 & 39.82 & 5.27 & $-15.98^{* * *}$ \\
\hline Adaptabilidad & 32.88 & 5.84 & 33.42 & 6.57 & $-13.19^{* *}$ \\
\hline Manejo del estrés & 27.16 & 5.73 & 31.49 & 5.10 & -1.41 \\
\hline Total cociente emocional & 53.28 & 5.98 & 58.85 & 6.35 & $-14.71^{* *}$ \\
\hline Estado de ánimo en general & 44.11 & 6.79 & 48.66 & 5.50 & $-13.19^{* * *}$ \\
\hline Impresión positiva & 16.03 & 3.11 & 17.31 & 2.97 & $-6.92^{* * *}$ \\
\hline \multicolumn{6}{|c|}{10 a 12 años ( $N=524$ para estatal; $N=529$ para particular $)$} \\
\hline Intrapersonal & 14.03 & 3.04 & 14.04 & 3.46 & -.33 \\
\hline Interpersonal & 35.61 & 5.95 & 39.09 & 4.74 & $-10.50^{* * *}$ \\
\hline Adaptabilidad & 32.62 & 5.56 & 34.33 & 5.77 & $-7.58^{* * *}$ \\
\hline Manejo del estrés & 27.78 & 4.96 & 30.06 & 4.81 & $-4.91^{* * *}$ \\
\hline Total cociente emocional & 54.01 & 6.29 & 57.32 & 6.26 & $-8.56^{* * *}$ \\
\hline Estado de ánimo en general & 44.06 & 7.08 & 47.52 & 5.78 & $-8.69^{* * *}$ \\
\hline Impresión positiva & 15.81 & 2.97 & 15.90 & 2.72 & -.53 \\
\hline \multicolumn{6}{|c|}{13 a 15 años ( $N=612$ para estatal; 256 para mujeres) } \\
\hline Intrapersonal & 14.19 & 2.92 & 14.69 & 3.49 & $-2.14^{*}$ \\
\hline Interpersonal & 35.12 & 5.75 & 38.49 & 4.50 & $-8.36^{\star \star \star}$ \\
\hline Adaptabilidad & 33.51 & 5.41 & 34.18 & 5.62 & $-8.17^{* * *}$ \\
\hline Manejo del estrés & 26.92 & 5.12 & 29.90 & 4.34 & -1.64 \\
\hline Total cociente emocional & 53.88 & 6.29 & 57.47 & $\begin{array}{l}4.04 \\
5.83\end{array}$ & $-7.82^{\star * *}$ \\
\hline Estado de ánimo en general & 42.91 & 6.97 & 46.37 & 5.45 & $-7.09^{* * *}$ \\
\hline Impresión positiva & 15.03 & 2.88 & 15.59 & 2.39 & $-2.70^{* *}$ \\
\hline \multicolumn{6}{|c|}{16 a 18 años ( $N=256$ para varones; 99 para mujeres) } \\
\hline Intrapersonal & 14.24 & 3.31 & 14.84 & 3.65 & -1.47 \\
\hline Interpersonal & 34.78 & 5.52 & 38.39 & 4.59 & $-6.57^{* * *}$ \\
\hline Adaptabilidad & 32.43 & 5.31 & 33.42 & 5.30 & $-4.61^{* *}$ \\
\hline Manejo del estrés & 26.79 & 5.06 & 29.42 & 4.09 & -1.57 \\
\hline Total cociente emocional & 53.27 & 6.34 & 57.20 & 5.94 & $-5.33^{\star * *}$ \\
\hline Estado de ánimo en general & 40.84 & 7.03 & 45.09 & 5.67 & $-5.37^{* * *}$ \\
\hline Impresión positiva & 14.81 & 2.83 & 15.28 & 2.47 & -1.45 \\
\hline
\end{tabular}

p. $.001^{* * *}$ p. $.01^{* *}$ p. $.05^{*}$

Tabla 11

Medias, desviaciones estándar y prueba t de Student de las escalas del Inventario BarOn: NA - Forma abreviada por grupos de edad y gestión

\begin{tabular}{|c|c|c|c|c|c|}
\hline \multirow[t]{2}{*}{$\begin{array}{c}\text { Grupo de edad } \\
\text { Escalas del BarOn ICE: NA }\end{array}$} & \multicolumn{2}{|c|}{ Estatal } & \multicolumn{2}{|c|}{ Particular } & \multirow[b]{2}{*}{$\mathrm{t}$} \\
\hline & $\mathrm{M}$ & $\mathrm{DE}$ & $\mathrm{M}$ & $\mathrm{DE}$ & \\
\hline \multicolumn{6}{|c|}{7 a 9 años $(\mathrm{N}=466$ para estatal; $\mathrm{N}=632$ para particular $)$} \\
\hline Intrapersonal & 14.01 & 3.32 & 15.11 & 3.28 & $-5.46^{\star * *}$ \\
\hline Interpersonal & 18.15 & 3.70 & 19.95 & 3.23 & $-8.58^{* * *}$ \\
\hline Adaptabilidad & 16.40 & 4.05 & 18.70 & 3.55 & $-10.02^{* * *}$ \\
\hline Manejo del estrés & 17.42 & 3.96 & 17.37 & 4.55 & .17 \\
\hline Total cociente emocional & 65.97 & 8.43 & 71.13 & 8.50 & $-9.98^{* * *}$ \\
\hline \multicolumn{6}{|c|}{10 a 12 años ( $\mathrm{N}=524$ para estatal; $\mathrm{N}=529$ para particular) } \\
\hline Intrapersonal & 14.03 & 3.04 & 14.03 & 3.47 & -.03 \\
\hline Interpersonal & 18.10 & 3.51 & 19.53 & 2.84 & $-7.30^{* * *}$ \\
\hline Adaptabilidad & 16.57 & 3.52 & 17.99 & 3.36 & $-6.69^{* * *}$ \\
\hline Manejo del estrés & 17.03 & 3.88 & 18.01 & 3.67 & $-4.24^{* * *}$ \\
\hline Total cociente emocional & 65.73 & 8.54 & 69.95 & 8.26 & $-7.41^{* * *}$ \\
\hline \multicolumn{6}{|c|}{13 a 15 años ( $N$ = 612 para estatal; 256 para mujeres) } \\
\hline Intrapersonal & 14.19 & 2.92 & 14.69 & 3.50 & $-2.145^{\star}$ \\
\hline Interpersonal & 17.74 & 3.23 & 18.92 & 2.85 & $-5.06^{* * *}$ \\
\hline Adaptabilidad & 15.94 & 3.49 & 17.72 & 2.94 & $-7.18^{\star \star *}$ \\
\hline Manejo del estrés & 17.63 & 3.72 & 17.87 & 3.45 & -.90 \\
\hline Total cociente emocional & 65.50 & 7.90 & 69.20 & 7.29 & $-6.432^{\star * *}$ \\
\hline \multicolumn{6}{|c|}{16 a 18 años ( $\mathrm{N}=256$ para varones; 99 para mujeres) } \\
\hline Intrapersonal & 14.24 & 3.31 & 14.84 & 3.65 & -1.48 \\
\hline Interpersonal & 17.81 & 3.28 & 19.22 & 2.79 & $-3.78^{* * *}$ \\
\hline Adaptabilidad & 15.66 & 3.57 & 17.64 & 2.62 & $-5.03^{\star * *}$ \\
\hline Manejo del estrés & 16.90 & 3.57 & 17.26 & 3.28 & -.89 \\
\hline Total cociente emocional & 64.61 & 8.32 & 68.97 & 7.52 & -4.54 \\
\hline
\end{tabular}

$\begin{array}{lll}\text { p. }<.001^{* * *} & \text { p. }<.01^{* *} \quad \text { p. }<.05^{\star}\end{array}$ 
Tabla 12

Medias, desviaciones estándar y prueba t de Student de las escalas del Inventario BarOn: NA - Forma abreviada por grupos de edad y gestión

\begin{tabular}{|c|c|c|c|c|}
\hline \multirow[t]{2}{*}{$\begin{array}{c}\text { Grupo de edad } \\
\text { Escalas del BarOn ICE: NA }\end{array}$} & \multicolumn{2}{|c|}{ Varón } & \multicolumn{2}{|c|}{ Mujer } \\
\hline & M & $\mathrm{DE}$ & M & $\mathrm{DE}$ \\
\hline \multicolumn{5}{|c|}{7 a 9 años ( $N=561$ para varones; $N=537$ para mujeres $)$} \\
\hline Intrapersonal & $14.56^{\mathrm{a}}$ & $3.60^{\mathrm{a}}$ & $14.26^{\mathrm{a}}$ & $3.57^{a}$ \\
\hline Interpersonal & $36.15^{\mathrm{a}}$ & $5.95^{\mathrm{a}}$ & $37.46^{\mathrm{a}}$ & $5.89^{a}$ \\
\hline Adaptabilidad & $29.33^{a}$ & $5.42^{\mathrm{a}}$ & $28.54^{\mathrm{a}}$ & $5.38^{a}$ \\
\hline Manejo del estrés & $32.63^{a}$ & $6.49^{a}$ & $33.36^{a}$ & $6.44^{\mathrm{a}}$ \\
\hline Total cociente emocional & $55.45^{\mathrm{a}}$ & $6.70^{\mathrm{a}}$ & $55.67^{a}$ & $6.65^{\mathrm{a}}$ \\
\hline Estado de ánimo en general & $45.36^{\mathrm{a}}$ & $6.92^{\mathrm{a}}$ & $46.32^{\mathrm{a}}$ & $6.86^{a}$ \\
\hline \multicolumn{5}{|c|}{10 a 12 años $(\mathrm{N}=564$ para varones; $\mathrm{N}=489$ para mujeres $)$} \\
\hline Intrapersonal & $14.13^{a}$ & $3.04^{a}$ & $13.90^{\mathrm{a}}$ & $3.03^{a}$ \\
\hline Interpersonal & $36.30^{\mathrm{a}}$ & $5.01^{\mathrm{a}}$ & $38.49^{a}$ & $4.50^{\mathrm{a}}$ \\
\hline Adaptabilidad & $29.04^{a}$ & $4.58^{\mathrm{a}}$ & $28.72^{\mathrm{a}}$ & $4.58^{a}$ \\
\hline Manejo del estrés & $33.54^{\mathrm{a}}$ & $5.49^{a}$ & $33.39^{a}$ & $5.48^{a}$ \\
\hline Total cociente emocional & $55.39^{a}$ & $5.65^{a}$ & $55.89^{a}$ & $5.64^{a}$ \\
\hline Estado de ánimo en general & $45.92^{a}$ & $5.84^{\mathrm{a}}$ & $45.56^{a}$ & $5.84^{a}$ \\
\hline \multicolumn{5}{|c|}{13 a 15 años $(\mathrm{N}=487$ para varones; $\mathrm{N}=381$ para mujeres $)$} \\
\hline Intrapersonal & $14.44^{\mathrm{a}}$ & $2.98^{a}$ & $14.53^{\mathrm{a}}$ & $2.99^{a}$ \\
\hline Interpersonal & $35.49^{\mathrm{a}}$ & $4.93^{\mathrm{a}}$ & $37.96^{\mathrm{a}}$ & $4.94^{\mathrm{a}}$ \\
\hline Adaptabilidad & $28.37^{a}$ & $4.48^{\mathrm{a}}$ & $28.07^{a}$ & $4.51^{\mathrm{a}}$ \\
\hline Manejo del estrés & $33.96^{\mathrm{a}}$ & $5.37^{\mathrm{a}}$ & $33.67^{a}$ & $5.39^{a}$ \\
\hline Total cociente emocional & $55.16^{\mathrm{a}}$ & $5.54^{\mathrm{a}}$ & $55.99^{\mathrm{a}}$ & $5.56^{a}$ \\
\hline Estado de ánimo en general & $44.86^{\mathrm{a}}$ & $5.72^{\mathrm{a}}$ & $44.03^{\mathrm{a}}$ & $5.74^{\mathrm{a}}$ \\
\hline \multicolumn{5}{|c|}{16 a 18 años $(N=181$ para varones; $N=174$ para mujeres $)$} \\
\hline Intrapersonal & $14.85^{\mathrm{a}}$ & $3.22^{\mathrm{a}}$ & $14.35^{\mathrm{a}}$ & $3.21^{a}$ \\
\hline Interpersonal & $35.02^{\mathrm{a}}$ & $5.31^{\mathrm{a}}$ & $38.22^{\mathrm{a}}$ & $5.40^{\mathrm{a}}$ \\
\hline Adaptabilidad & $27.81^{\mathrm{a}}$ & $4.65^{\mathrm{a}}$ & $25.52^{\mathrm{a}}$ & $5.22^{a}$ \\
\hline Manejo del estrés & $33.56^{\mathrm{a}}$ & $5.19^{a}$ & $32.18^{a}$ & $5.37^{a}$ \\
\hline Total cociente emocional & $54.87^{a}$ & $6.49^{a}$ & $55.55^{a}$ & $6.43^{a}$ \\
\hline Estado de ánimo en general & $42.97^{a}$ & $6.58^{a}$ & $42.70^{\mathrm{a}}$ & $7.31^{a}$ \\
\hline
\end{tabular}

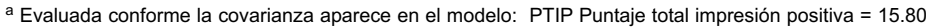

Tabla 13

Medias y desviaciones estándar obtenidas mediante el Ancova de las escalas del Inventario BarOn: NA - Forma abreviada por grupos de edad y sexo

\begin{tabular}{|c|c|c|c|c|}
\hline \multirow[t]{2}{*}{$\begin{array}{c}\text { Grupo de edad } \\
\text { Escalas del BarOn ICE: NA }\end{array}$} & \multicolumn{2}{|c|}{ Varón } & \multicolumn{2}{|c|}{ Mujer } \\
\hline & M & $\mathrm{DE}$ & M & $\mathrm{DE}$ \\
\hline \multicolumn{5}{|c|}{7 a 9 años $(\mathrm{N}=561$ para varones; $\mathrm{N}=537$ para mujeres $)$} \\
\hline Intrapersonal & $14.56^{\mathrm{a}}$ & $3.60^{\mathrm{a}}$ & $14.26^{\mathrm{a}}$ & $3.57^{\mathrm{a}}$ \\
\hline Interpersonal & $18.35^{a}$ & $3.46^{\mathrm{a}}$ & $19.31^{\mathrm{a}}$ & $3.43^{a}$ \\
\hline Adaptabilidad & $17.46^{\mathrm{a}}$ & $3.74^{\mathrm{a}}$ & $17.02^{\mathrm{a}}$ & $3.71^{\mathrm{a}}$ \\
\hline Manejo del estrés & $17.03^{a}$ & $4.38^{a}$ & $17.69^{a}$ & $4.33^{a}$ \\
\hline Total cociente emocional & $67.41^{\mathrm{a}}$ & $8.81^{\mathrm{a}}$ & $68.28^{a}$ & $8.74^{\mathrm{a}}$ \\
\hline \multicolumn{5}{|c|}{10 a 12 años ( $N=564$ para varones; $N=489$ para mujeres $)$} \\
\hline Intrapersonal & $14.13^{\mathrm{a}}$ & $3.04^{a}$ & $13.90^{\mathrm{a}}$ & $3.03^{a}$ \\
\hline Interpersonal & $18.19^{a}$ & $2.92^{\mathrm{a}}$ & $19.50^{\mathrm{a}}$ & $2.92^{\mathrm{a}}$ \\
\hline Adaptabilidad & $17.43^{\mathrm{a}}$ & $3.16^{\mathrm{a}}$ & $17.07^{a}$ & $3.14^{\mathrm{a}}$ \\
\hline Manejo del estrés & $17.54^{\mathrm{a}}$ & $3.68^{a}$ & $17.51^{\mathrm{a}}$ & $3.69^{a}$ \\
\hline Total cociente emocional & $67.28^{\mathrm{a}}$ & $7.43^{a}$ & $67.97^{\mathrm{a}}$ & $7.43^{a}$ \\
\hline \multicolumn{5}{|c|}{13 a 15 años ( $N=487$ para varones; 381 para mujeres) } \\
\hline Intrapersonal & $14.44^{\mathrm{a}}$ & $2.98^{a}$ & $14.53^{a}$ & $2.99 a$ \\
\hline Interpersonal & $17.59^{\mathrm{a}}$ & $2.87^{\mathrm{a}}$ & $19.26^{\mathrm{a}}$ & $2.87^{\mathrm{a}}$ \\
\hline Adaptabilidad & $16.90^{\mathrm{a}}$ & $3.09^{a}$ & $16.58^{a}$ & $3.10^{\mathrm{a}}$ \\
\hline Manejo del estrés & $17.76^{\mathrm{a}}$ & $3.62^{a}$ & $17.69^{a}$ & $3.63^{a}$ \\
\hline Total cociente emocional & $66.69^{a}$ & $7.29^{\mathrm{a}}$ & $68.06^{\mathrm{a}}$ & $7.30^{\mathrm{a}}$ \\
\hline \multicolumn{5}{|c|}{16 a 18 años ( $N=181$ para varones; 174 para mujeres $)$} \\
\hline Intrapersonal & $14.85^{\mathrm{a}}$ & $3.22^{\mathrm{a}}$ & $14.35^{\mathrm{a}}$ & $3.21^{\mathrm{a}}$ \\
\hline Interpersonal & $17.44^{\mathrm{a}}$ & $3.08^{a}$ & $19.67^{a}$ & $3.07^{a}$ \\
\hline Adaptabilidad & $16.56^{\mathrm{a}}$ & $3.32^{\mathrm{a}}$ & $16.73^{a}$ & $3.32^{\mathrm{a}}$ \\
\hline Manejo del estrés & $17.48^{a}$ & $3.89^{a}$ & $16.58^{a}$ & $\begin{array}{l}0.02 \\
3.89 a\end{array}$ \\
\hline Total cociente emocional & $66.34^{a}$ & $7.83^{\mathrm{a}}$ & $67.33^{a}$ & $7.84^{a}$ \\
\hline
\end{tabular}

a Evaluada conforme la covarianza aparece en el modelo: PTIP Puntaje total impresión positiva $=15.80$ 
Tabla 14

Medias y desviaciones estándar obtenidas mediante el Ancova de las escalas del Inventario BarOn: NA - Forma completa por grupos de edad y sexo

\begin{tabular}{|c|c|c|c|c|}
\hline \multirow[t]{2}{*}{$\begin{array}{c}\text { Grupo de edad } \\
\text { Escalas del BarOn ICE: NA }\end{array}$} & \multicolumn{2}{|c|}{ Varón } & \multicolumn{2}{|c|}{ Mujer } \\
\hline & $\mathrm{M}$ & $\mathrm{DE}$ & $\mathrm{M}$ & $\mathrm{DE}$ \\
\hline \multicolumn{5}{|c|}{7 a 9 años $(\mathrm{N}=561$ para varones; $\mathrm{N}=537$ para mujeres $)$} \\
\hline Intrapersonal & $14.01^{a}$ & $3.32^{a}$ & $15.11^{\mathrm{a}}$ & $3.28^{a}$ \\
\hline Interpersonal & $34.42^{\mathrm{a}}$ & $5.88^{a}$ & $39.82^{\mathrm{a}}$ & $5.27^{a}$ \\
\hline Adaptabilidad & $27.16^{a}$ & $5.73^{\mathrm{a}}$ & $31.49^{a}$ & $5.10^{\mathrm{a}}$ \\
\hline Manejo del estrés & $32.88^{a}$ & $5.84^{a}$ & $33.42^{a}$ & $6.57^{a}$ \\
\hline Total cociente emocional & $53.28^{a}$ & $5.99^{a}$ & $58.85^{a}$ & $6.35^{\mathrm{a}}$ \\
\hline Estado de ánimo en general & $44.11^{a}$ & $6.80^{\mathrm{a}}$ & $46.66^{a}$ & $6.51^{\mathrm{a}}$ \\
\hline \multicolumn{5}{|c|}{10 a 12 años ( $N=524$ para estatal; $N=529$ para particular $)$} \\
\hline Intrapersonal & $14.03^{a}$ & $3.04^{a}$ & $14.04^{\mathrm{a}}$ & $3.47^{a}$ \\
\hline Interpersonal & $35.61^{\mathrm{a}}$ & $5.95^{\mathrm{a}}$ & $39.09^{a}$ & $4.74^{\mathrm{a}}$ \\
\hline Adaptabilidad & $27.78 \mathrm{a}$ & $4.96^{\mathrm{a}}$ & $30.06^{\mathrm{a}}$ & $4.81^{a}$ \\
\hline Manejo del estrés & $32.62^{\mathrm{a}}$ & $5.56^{\mathrm{a}}$ & $34.33^{a}$ & $5.76^{\mathrm{a}}$ \\
\hline Total cociente emocional & $54.01^{\mathrm{a}}$ & $6.29^{a}$ & $57.32^{\mathrm{a}}$ & $6.26^{\mathrm{a}}$ \\
\hline Estado de ánimo en general & $44.06^{a}$ & $7.08^{a}$ & $47.52^{\mathrm{a}}$ & $5.78^{\mathrm{a}}$ \\
\hline \multicolumn{5}{|c|}{13 a 15 años ( $N=612$ para estatal; 256 para particular) } \\
\hline Intrapersonal & $14.19^{\mathrm{a}}$ & $2.93^{a}$ & $14.59^{\mathrm{a}}$ & $3.49^{\mathrm{a}}$ \\
\hline Interpersonal & $35.12^{\mathrm{a}}$ & $5.75^{a}$ & $38.49^{a}$ & $4.51^{\mathrm{a}}$ \\
\hline Adaptabilidad & $26.92^{\mathrm{a}}$ & $5.12^{\mathrm{a}}$ & $29.90^{\mathrm{a}}$ & $4.34^{a}$ \\
\hline Manejo del estrés & $33.51^{\mathrm{a}}$ & $5.42^{\mathrm{a}}$ & $34.18^{\mathrm{a}}$ & $5.62^{\mathrm{a}}$ \\
\hline Total cociente emocional & $53.88^{\mathrm{a}}$ & $6.29^{a}$ & $57.47^{\mathrm{a}}$ & $5.83^{a}$ \\
\hline Estado de ánimo en general & $42.91^{\mathrm{a}}$ & $6.96^{a}$ & $46.37^{a}$ & $5.45^{\mathrm{a}}$ \\
\hline \multicolumn{5}{|c|}{16 a 18 años ( $N=256$ para estatal; 99 para particular) } \\
\hline Intrapersonal & $14.24^{\mathrm{a}}$ & $3.31^{\mathrm{a}}$ & $14.84^{\mathrm{a}}$ & $3.65^{\mathrm{a}}$ \\
\hline Interpersonal & $34.78^{\mathrm{a}}$ & $5.52^{\mathrm{a}}$ & $38.89^{a}$ & $4.59^{a}$ \\
\hline Adaptabilidad & $26.79^{a}$ & $5.06^{a}$ & $29.42^{\mathrm{a}}$ & $4.09^{a}$ \\
\hline Manejo del estrés & $32.43^{\mathrm{a}}$ & $5.31^{\mathrm{a}}$ & $33.42^{\mathrm{a}}$ & $5.30^{\mathrm{a}}$ \\
\hline Total cociente emocional & $53.27^{a}$ & $6.34^{\mathrm{a}}$ & $57.20^{\mathrm{a}}$ & $5.94^{\mathrm{a}}$ \\
\hline Estado de ánimo en general & $40.84^{a}$ & $7.03^{a}$ & $45.09^{a}$ & $5.68^{\mathrm{a}}$ \\
\hline
\end{tabular}

a Evaluada conforme la covarianza aparece en el modelo: PTIP Puntaje total impresión positiva = 15.80

Tabla 15

Medias y desviaciones estándar obtenidas mediante el Ancova de las escalas del Inventario BarOn: NA - Forma abreviada por grupos de edad y gestión

\begin{tabular}{|c|c|c|c|c|}
\hline \multirow[t]{2}{*}{$\begin{array}{c}\text { Grupo de edad } \\
\text { Escalas del BarOn ICE: NA }\end{array}$} & \multicolumn{2}{|c|}{ Varón } & \multicolumn{2}{|c|}{ Mujer } \\
\hline & M & DE & M & $\mathrm{DE}$ \\
\hline \multicolumn{5}{|c|}{7 a 9 años $(\mathrm{N}=466$ para estatal; $\mathrm{N}=632$ para particular $)$} \\
\hline Intrapersonal & $14.01^{\mathrm{a}}$ & $3.32 \mathrm{a}$ & $15.11 \mathrm{a}$ & $3.28 \mathrm{a}$ \\
\hline Interpersonal & $18.14 \mathrm{a}$ & $3.70 \mathrm{a}$ & $19.95 \mathrm{a}$ & $3.24 \mathrm{a}$ \\
\hline Adaptabilidad & $16.40 \mathrm{a}$ & $4.06 \mathrm{a}$ & $18.70 \mathrm{a}$ & $3.55 \mathrm{a}$ \\
\hline Manejo del estrés & $17.42 \mathrm{a}$ & $3.96 \mathrm{a}$ & $17.37 \mathrm{a}$ & $4.55 \mathrm{a}$ \\
\hline Total cociente emocional & 65.97 a & $8.42 \mathrm{a}$ & $71.13 \mathrm{a}$ & $8.50 \mathrm{a}$ \\
\hline \multicolumn{5}{|c|}{10 a 12 años $(\mathrm{N}=524$ para estatal; $\mathrm{N}=529$ para particular $)$} \\
\hline Intrapersonal & $14.03 \mathrm{a}$ & $3.04 \mathrm{a}$ & $14.68 \mathrm{a}$ & $3.46 \mathrm{a}$ \\
\hline Interpersonal & $18.01 \mathrm{a}$ & $3.51 \mathrm{a}$ & $19.53 \mathrm{a}$ & $2.83 \mathrm{a}$ \\
\hline Adaptabilidad & $16.57 \mathrm{a}$ & $3.67 \mathrm{a}$ & $17.99 \mathrm{a}$ & $3.58 \mathrm{a}$ \\
\hline Manejo del estrés & $17.03 \mathrm{a}$ & $3.68 \mathrm{a}$ & $18.01 \mathrm{a}$ & $3.68 \mathrm{a}$ \\
\hline Total cociente emocional & 65.73 a & $8.54 \mathrm{a}$ & 69.57 a & $8.26 \mathrm{a}$ \\
\hline \multicolumn{5}{|c|}{13 a 15 años ( $N=612$ para estatal; 256 para particular) } \\
\hline Intrapersonal & 14.19 a & $2.93 \mathrm{a}$ & $14.69 \mathrm{a}$ & $3.49 \mathrm{a}$ \\
\hline Interpersonal & $17.74 \mathrm{a}$ & $3.23 \mathrm{a}$ & $18.92 \mathrm{a}$ & $2.85 \mathrm{a}$ \\
\hline Adaptabilidad & $15.94 \mathrm{a}$ & $3.49 \mathrm{a}$ & $17.72 \mathrm{a}$ & $2.94 \mathrm{a}$ \\
\hline Manejo del estrés & $17.63 \mathrm{a}$ & $3.72 \mathrm{a}$ & $17.87 \mathrm{a}$ & $3.45 \mathrm{a}$ \\
\hline Total cociente emocional & $65.50 \mathrm{a}$ & $7.90 \mathrm{a}$ & $69.20 \mathrm{a}$ & $7.29 \mathrm{a}$ \\
\hline \multicolumn{5}{|c|}{16 a 18 años ( $\mathrm{N}=256$ para estatal; 99 para particular) } \\
\hline Intrapersonal & $14.24 \mathrm{a}$ & $3.31 \mathrm{a}$ & $14.84 \mathrm{a}$ & $3.65 \mathrm{a}$ \\
\hline Interpersonal & $17.81 \mathrm{a}$ & $3.28 \mathrm{a}$ & $19.22 \mathrm{a}$ & $2.79 \mathrm{a}$ \\
\hline Adaptabilidad & $15.66 \mathrm{a}$ & $3.57 \mathrm{a}$ & $17.64 \mathrm{a}$ & $2.62 \mathrm{a}$ \\
\hline Manejo del estrés & $16.90 \mathrm{a}$ & $3.57 \mathrm{a}$ & $17.26 \mathrm{a}$ & $3.28 \mathrm{a}$ \\
\hline Total cociente emocional & $64.62 \mathrm{a}$ & $8.32 \mathrm{a}$ & $68.97 \mathrm{a}$ & $7.52 \mathrm{a}$ \\
\hline
\end{tabular}

a Evaluada conforme la covarianza aparece en el modelo: PTIP Puntaje total impresión positiva $=15.80$ 
Efectos de la edad y el sexo

En la siguiente sección se describen los efectos de la edad y el sexo en las distintas escalas del BarOn ICE: NA. Para investigar si existen diferencias entre los grupos, considerando la edad o el sexo, se llevó a cabo una serie de análisis de varianza de dos vías (sexo por grupos de edad y gestión por grupos de edad). El Anova de dos rutas simultáneamente permite el análisis de dos factores y brinda información sobre la interacción entre ellos. Debido a que la edad y el sexo o la edad y la gestión tienen en gran medida efectos diferenciadores se han considerado normas por separado.

Los resultados específicos tanto para el sexo como para la gestión en los grupos de edad para las diferentes esca- las del inventario se describen en las tablas 16 al 19, en las que se incluyen los efectos del tamaño de la muestra $\left(\mathrm{Eta}^{2}\right)$ para los efectos principales significativos (sexo o edad), que resumen la fuerza general de la relación ( Eta $^{2}$ varía entre 0 y 1.0 donde cero representa ninguna relación y uno la relación perfecta).

\section{Forma completa del ICE: NA}

Cuando se examinan los resultados presentados en la tabla 16 , se observa la significación de los efectos principales considerando el sexo. Los varones tienen un puntaje más elevado en las escalas intrapersonal, adaptabilidad, manejo del estrés e impresión positiva; las mujeres en cambio denotan puntajes medios más elevados en la escala interpersonal (tabla 13). Así mismo, se halló un

\section{Tabla 16}

Análisis univariado de varianza: Prueba F, niveles de significación, coeficientes Eta ${ }^{2}$ y prueba Student-Newman Keuls de las escalas del Inventario BarOn: NA - Forma completa para los grupos de edad y sexo

\begin{tabular}{|c|c|c|c|c|c|c|c|c|c|c|}
\hline \multirow{2}{*}{$\begin{array}{l}\text { Escalas del } \\
\text { BarOn ICE: NA }\end{array}$} & \multicolumn{3}{|c|}{$\begin{array}{l}\text { Efecto principal } \\
\text { Sexo }\end{array}$} & \multicolumn{3}{|c|}{$\begin{array}{l}\text { Efecto principal } \\
\text { Grupos de edad }\end{array}$} & \multicolumn{3}{|c|}{$\begin{array}{l}\text { Interacciones } \\
\text { Sexo x G. edad }\end{array}$} & \multirow{2}{*}{$\begin{array}{c}{ }^{\mathrm{a}} \text { Múltiples } \\
\text { comparaciones } \\
(\mathrm{SNK})\end{array}$} \\
\hline & $\overline{F(1.3366)}$ & Sig. & Eta & $F(3.3366)$ & Sig. & Eta & $F(3.3366)$ & Sig. & $\mathrm{Eta}^{2}$ & \\
\hline Intrapersonal & 5.68 & .05 & .002 & 6.04 & .001 & .005 & -- & N.S & -- & $2<1$ \\
\hline Interpersonal & 91.84 & .001 & .091 & 14.41 & .001 & .013 & 4.18 & .05 & .004 & $4,3<2,1$ \\
\hline Adaptabilidad & - & N.S. & - & 26.01 & .001 & .023 & 2.86 & .05 & .003 & $3,4<2<1$ \\
\hline Manejo del estrés & -- & N.S & -- & 2.99 & .05 & .003 & 2.71 & .05 & .002 & $4<2,3$ \\
\hline $\begin{array}{l}\text { Puntaje total } \\
\text { emocional }\end{array}$ & - & N.S. & -- & 12.49 & .001 & .011 & -- & N.S. & -- & $3,4<2<1$ \\
\hline $\begin{array}{l}\text { Estado de ánimo en } \\
\text { general }\end{array}$ & - & N.S. & -- & 57.68 & .001 & .049 & -- & N.S. & -- & $4<3<2<1$ \\
\hline Impresión positiva & 5.78 & .05 & .008 & 58.78 & .001 & .05 & -- & N.S. & -- & $4,3<2,1$ \\
\hline
\end{tabular}

La edad de los grupos se ha ordenado de la media más baja a la más alta, el signo "< " indica que existe una diferencia significativa ( $p<$ $.001, p<.01, p<.05)$, la edad de los grupos separados por una coma no difieren significativamente. Las siglas N.S. señalan efectos no significativos.

a Edad de los grupos $1=7$ a 9 años; 2 = 10 a 12 años; $3=13$ a 15 años; $4=16$ a 18 años. 
efecto principal para los grupos de edad en todas las escalas, incluyendo el puntaje total emocional y la impresión positiva. La interacción sexo y grupo de edad fue significativa para las escalas interpersonal, adaptabilidad y manejo del estrés. Las múltiples comparaciones mediante el procedimiento StudentNewman Keuls (SNK) halló diferencias entre los siguientes grupos de edades: en la escala intrapersonal el grupo de 10 a 12 años tuvo puntajes más bajos que el de 7 a 9 años; en interpersonal no se halló diferencias entre los grupos de edad 16 a 18 con 13 a 15 años, ni entre 10 a 12 y 7 a 9 años; pero sí hubo diferencias significativas entre los dos primeros grupos de edad en comparación con los dos grupos menores. En la escala de adaptabilidad los grupos de edad: 13 a
15 y 16 a 18 años presentaron puntajes medios menos elevados que el de 10 a 12 y este a su vez fue menor que el de 7 a 9 años. En manejo del estrés el grupo de 16 a 18 años observó puntajes medios más bajos que los de 10 a 12 y 13 a 15 años. En el puntaje emocional total los de 13 a 15 y 16 a 18 años obtuvieron puntajes medios más bajos que los de 10 a 12 y 7 a 9 años. En cuanto al estado de ánimo en general los mayores denotaron más bajos puntajes en relación a los menores. En cuanto a impresión positiva los mayores (grupos de 16 a 18 y 14 a 15 años) tienden a dar una menor impresión positiva que los menores ( 7 a 9 y 10 a 12 años).

Cuando se examinan los efectos principales considerando el tipo de gestión (tabla 17) las diferencias son

Tabla 17

Análisis univariado de varianza: Prueba F, niveles de significación, coeficientes Eta ${ }^{2}$ y prueba Student - Newman Keuls de las escalas del Inventario BarOn: NA - Forma completa para los grupos de edad y gestión.

\begin{tabular}{|c|c|c|c|c|c|c|c|c|c|c|}
\hline \multirow{2}{*}{$\begin{array}{c}\text { Escalas del } \\
\text { BarOn ICE: NA }\end{array}$} & \multicolumn{3}{|c|}{$\begin{array}{c}\text { Efecto principal } \\
\text { Gestión }\end{array}$} & \multicolumn{3}{|c|}{$\begin{array}{l}\text { Efecto principal } \\
\text { Grupos de Edad }\end{array}$} & \multicolumn{3}{|c|}{$\begin{array}{c}\text { Interacciones } \\
\text { Gestión x G. edad } \\
\end{array}$} & \multirow{2}{*}{$\begin{array}{c}{ }^{a} \text { Múltiples } \\
\text { comparaciones } \\
\text { (SNK) }\end{array}$} \\
\hline & $F(1.3366)$ & Sig. & Eta & $F(3.3366)$ & Sig. & Eta & $F(3.3366)$ & Sig. & Eta & \\
\hline Intrapersonal & 16.92 & .001 & .005 & 5.35 & .001 & .005 & 4.68 & .01 & .004 & $2<1$ \\
\hline Interpersonal & 335.44 & .001 & .091 & -- & N.S. & -- & 6.57 & .001 & .006 & $4,3<2,1$ \\
\hline Adaptabilidad & 218.59 & .001 & .061 & 6.76 & .001 & .006 & 7.06 & .001 & .006 & $4,3<2<1$ \\
\hline Manejo del estrés & 17.12 & .001 & .005 & 2.892 & .05 & .003 & -- & N.S. & -- & $4<2,3$ \\
\hline $\begin{array}{l}\text { Puntaje total } \\
\text { emocional }\end{array}$ & 256.305 & .001 & .071 & -- & N.S. & -- & 6.02 & .001 & .005 & $4,3<2<1$ \\
\hline $\begin{array}{l}\text { Estado de ánimo } \\
\text { en general }\end{array}$ & 221.06 & .001 & .062 & 25.585 & .001 & .022 & -- & N.S. & -- & $4<3<2<1$ \\
\hline Impresión positiva & 25.87 & .001 & .008 & 41.01 & .001 & .035 & 7.12 & .001 & .006 & $4,3<2,1$ \\
\hline
\end{tabular}

La edad de los grupos se ha ordenado de la media más baja a la más alta, el signo "<" indica que existe una diferencia significativa $(p<.001, p<.01, p<.05)$, la edad de los grupos separados por una coma no difieren significativamente. Las siglas N.S. señalan efectos no significativos.

a Edad de los grupos 1 = 7 a 9 años; 2 = 10 a 12 años; $3=13$ a 15 años; 4 = 16 a 18 años. 
significativas al uno por ciento para las diferentes escalas del BarOn ICE: NA $\mathrm{y}$ también para el puntaje emocional total, estado de ánimo general e impresión positiva a favor de los colegios particulares. Los efectos principales de la edad arrojan diferencias significativas en los componentes intrapersonal, adaptabilidad, manejo del estrés, estado de ánimo general e impresión positiva. La interacción gestión y grupos de edad fue significativa para las escalas intrapersonal, interpersonal, adaptabilidad e impresión positiva, y para el puntaje total emocional. En las múltiples comparaciones con la prueba SNK se observa que los puntajes medios son más elevados para los grupos de edad menores que para los mayores.

\section{Forma abreviada del ICE: NA}

Los resultados de la tabla 18 permiten apreciar los efectos principales considerando el sexo en la versión abreviada. Los puntajes medios para las cuatro escalas y para el puntaje total emocional son más elevados para los colegios particulares (tabla 14). Cuando se examinan los efectos principales de la edad, las diferencias son significativas en las escalas intrapersonal, interpersonal, adaptabilidad y en el puntaje total emocional. Las interacciones gestión y grupos de edad presentan diferencias significativas en adaptabilidad y manejo del estrés, y en las múltiples comparaciones mediante el procedimiento del SNK se observa la misma dirección con respecto al ordenamiento de las medias para las diferentes escalas y el

Tabla 18

Análisis univariado de varianza: Prueba F, niveles de significación, coeficientes Eta ${ }^{2}$ y prueba Student-Newman Keuls de las escalas del Inventario BarOn: NA - Forma abreviada para los grupos de edad y sexo

\begin{tabular}{|c|c|c|c|c|c|c|c|c|c|c|}
\hline \multirow{2}{*}{$\begin{array}{c}\text { Escalas del } \\
\text { BarOn ICE: NA }\end{array}$} & \multicolumn{3}{|c|}{$\begin{array}{l}\text { Efecto principal } \\
\text { Sexo }\end{array}$} & \multicolumn{3}{|c|}{$\begin{array}{l}\text { Efecto principal } \\
\text { Grupos de edad }\end{array}$} & \multicolumn{3}{|c|}{$\begin{array}{l}\text { Interacciones } \\
\text { Sexo x G. Edad }\end{array}$} & \multirow{2}{*}{$\begin{array}{c}{ }^{\mathrm{a}} \text { Múltiples } \\
\text { comparaciones } \\
(\mathrm{SNK})\end{array}$} \\
\hline & $F(1.3366)$ & Sig. & Eta & $F(3.3366)$ & Sig. & Eta & $F(3.3366)$ & Sig. & Eta & \\
\hline Intrapersonal & 5.68 & .05 & .002 & 6.04 & .001 & .005 & -- & N.S & -- & $2<1$ \\
\hline Interpersonal & 134.63 & .001 & .038 & 18.41 & .001 & .016 & 5.06 & .01 & .004 & $3,4<2<1$ \\
\hline Adaptabilidad & 7.31 & .05 & .002 & 27.37 & .001 & .024 & -- & N.S. & .003 & $4,3<2<1$ \\
\hline Manejo del estrés & -- & N.S & -- & 3.67 & .05 & .003 & 3.59 & .05 & .003 & $4<2,3$ \\
\hline $\begin{array}{l}\text { Puntaje total } \\
\text { emocional }\end{array}$ & 4.37 & .05 & .001 & 16.53 & .05 & .015 & -- & N.S. & -- & $4,3<2<1$ \\
\hline
\end{tabular}

La edad de los grupos se ha ordenado de la media más baja a la más alta, el signo "<" indica que existe una diferencia significativa $(p<.001, p<.01, p<.05)$, la edad de los grupos separados por una coma no difieren significativamente. Las siglas N.S. señalan efectos no significativos.

a Edad de los grupos 1 = 7 a 9 años; 2 = 10 a 12 años; 3 = 13 a 15 años; 4 = 16 a 18 años. 
Tabla 19

Análisis univariado de varianza: Prueba F, niveles de significación, coeficientes Eta ${ }^{2}$ y prueba Student-Newman Keuls de las escalas del Inventario BarOn: NA - Forma abreviada para los grupos de edad y gestión

\begin{tabular}{|c|c|c|c|c|c|c|c|c|c|c|}
\hline \multirow{2}{*}{$\begin{array}{l}\text { Escalas del } \\
\text { BarOn ICE: NA }\end{array}$} & \multicolumn{3}{|c|}{$\begin{array}{c}\text { Efecto principal } \\
\text { Gestión }\end{array}$} & \multicolumn{3}{|c|}{$\begin{array}{l}\text { Efecto principal } \\
\text { Grupos de edad }\end{array}$} & \multicolumn{3}{|c|}{$\begin{array}{c}\text { Interacciones } \\
\text { Gestión x G. edad }\end{array}$} & \multirow{2}{*}{$\begin{array}{c}{ }^{\mathrm{a}} \text { Múltiples } \\
\text { comparaciones } \\
\text { (SNK) }\end{array}$} \\
\hline & $F(1.3366)$ & Sig. & Eta & $F(3.3366)$ & Sig. & Eta & $\mathrm{F}(3.3366)$ & Sig. & Eta & \\
\hline Intrapersonal & 16.92 & .001 & .005 & 5.35 & .001 & .005 & 4.68 & .01 & .004 & $2<1$ \\
\hline Interpersonal & 119.50 & .001 & .034 & 7.60 & .001 & .007 & -- & N.S. & -- & $3,4<2<1$ \\
\hline Adaptabilidad & 169.78 & .001 & .048 & 8.45 & .001 & .007 & 2.72 & .05 & .002 & $4,3<2<1$ \\
\hline Manejo del estrés & 5.92 & .05 & .002 & - & N.S. & -- & 3.20 & .05 & .003 & $4<2,3$ \\
\hline $\begin{array}{l}\text { Puntaje total } \\
\text { emocional }\end{array}$ & 159.60 & .001 & .045 & 4.72 & .01 & .004 & -- & N.S. & -- & $4,3<2<1$ \\
\hline
\end{tabular}

La edad de los grupos se ha ordenado de la media más baja a la más alta, el signo "<" indica que existe una diferencia significativa $(p<.001, p<.01, p<.05)$, la edad de los grupos separados por una coma no difieren significativamente. Las siglas N.S. señalan efectos no significativos.

a Edad de los grupos 1 = 7 a 9 años; 2 = 10 a 12 años; 3 = 13 a 15 años; 4 = 16 a 18 años.

puntaje total, favoreciendo a los grupos de menor edad.

En la tabla 19 se observan los efectos principales considerando la gestión en la versión abreviada. Los resultados para la escala intrapersonal fueron los mismos que para la versión completa del Inventario BarOn ICE: NA, dado que está integrado por los mismos elementos. Solo en la escala interpersonal $y$ en el puntaje total emocional se hallaron efectos principales a favor de las mujeres, mientras que en adaptabilidad los varones obtuvieron puntajes más favorables. Cuando se examinan los efectos principales de la edad, las diferencias son significativas en las distintas escalas, incluyendo el puntaje total emocional. La interacción sexo y grupo de edad solo arroja diferencias significativas para la escalas interpersonal. Las múltiples comparaciones mediante el procedimiento el SNK muestran las mismas tendencias en los grupos de edad que en la versión completa.

\section{Propiedades PSICOMÉTRICAS DEL \\ BARON ICE: NA}

\section{Confiabilidad}

El propósito de estudiar la confiabilidad es examinar en qué medida las diferencias individuales de los puntajes en un test pueden ser atribuidas a las diferencias "verdaderas" de las características consideradas. En el extranjero BarOn y Parker (2000) realizaron un estudio sobre cuatro tipos de confiabilidad: consistencia interna, media de las correlaciones inter-ítem, confiabilidad testretest, y además establecieron el error estándar de medición/predicción, que se presentan de modo detallado en el $M a$ nual técnico de la prueba original.

En esta investigación se ha procedido a realizar el mismo análisis, excep- 
tuando la confiabilidad test-retest. Cabe mencionar que en el trabajo de BarOn y Parker (2000) el retest efectuado en una muestra de 60 niños cuya edad promedio fue 13.5 años, reveló la estabilidad del inventario, oscilando los coeficientes entre $.77 \mathrm{y} .88$ tanto para la forma completa como para la abreviada. En cambio, en las muestras normativas peruanas, además de los efectos del sexo y los grupos de edad, se ha procedido a examinar también los efectos de la gestión y los grupos de edad.

\section{Consistencia interna}

Se refiere al grado en que todos los ítemes de una escala particular miden consistentemente el mismo constructo. La consistencia interna fue medida con el Alfa de Cronbach, que es la sumatoria general de los coeficientes que varían

Tabla 20

Coeficiente de consistencia interna para las escalas del

BarOn ICE: NA - Forma completa (por grupos de edad y sexo)

\begin{tabular}{lcccc}
\hline $\begin{array}{c}\text { Sexo } \\
\text { BarOn ICE: NA }\end{array}$ & $\begin{array}{c}7 \text { a } 9 \\
\text { años }\end{array}$ & $\begin{array}{c}10 \text { a 12 } \\
\text { años }\end{array}$ & $\begin{array}{c}13 \text { a } 15 \\
\text { años }\end{array}$ & $\begin{array}{c}16 \text { a } 18 \\
\text { años }\end{array}$ \\
\hline $\begin{array}{l}\text { Varones } \\
\text { Intrapersonal }\end{array}$ & .23 & .41 & .46 & .56 \\
Interpersonal & .69 & .68 & .72 & .70 \\
Adaptabilidad & .71 & .71 & .75 & .73 \\
Manejo del estrés & .62 & .63 & .68 & .69 \\
C.E. total & .70 & .77 & .77 & .78 \\
Estado de ánimo & .84 & .86 & .87 & .88 \\
general & & & & \\
Mujeres & & & & .47 \\
Intrapersonal & .27 & .46 & .73 & .71 \\
Interpersonal & .68 & .70 & .73 \\
Adaptabilidad & .69 & .70 & .76 & .80 \\
Manejo del estrés & .63 & .71 & .68 & .67 \\
C.E. total & .70 & .76 & .73 & .79 \\
Estado de ánimo & .82 & .86 & .87 & .87 \\
general & & & &
\end{tabular}

entre 0.00 (confiabilidad muy baja) y 1.00 (confiabilidad perfecta). La consistencia interna de una escala particular es función tanto de la calidad de los ítemes como de la validez de las respuestas del evaluado.

La tabla 20 presenta los coeficientes de consistencia interna para las diversas escalas del BarOn ICE: NA - forma completa, con excepción del Índice de inconsistencia y de la Escala de impresión positiva. Por el modo en que han sido calculados el Índice de inconsistencia (suma de las diferencias absolutas entre los pares de ítems seleccionados) y la Escala de impresión positiva (suma de un conjunto de ítems cuyas respuestas no son típicamente esperadas por niños o adolescentes), no resulta apropiado tomarlos en cuenta para determinar los coeficientes de confiabilidad. La tabla 21 presenta los

Tabla 21

Coeficiente de consistencia interna para las escalas del

BarOn ICE: NA - Forma abreviada (por grupos de edad y sexo)

\begin{tabular}{lcccc}
\hline $\begin{array}{c}\text { Sexo } \\
\begin{array}{c}\text { Escalas del } \\
\text { BarOn ICE: NA }\end{array}\end{array}$ & $\begin{array}{c}7 \text { a } 9 \\
\text { años }\end{array}$ & $\begin{array}{c}10 \text { a } 12 \\
\text { años }\end{array}$ & $\begin{array}{c}13 \text { a } 15 \\
\text { años }\end{array}$ & $\begin{array}{c}16 \text { a } 18 \\
\text { años }\end{array}$ \\
\hline Varones & & & & \\
Intrapersonal & .23 & .41 & .46 & .56 \\
Interpersonal & .58 & .58 & .58 & .58 \\
Adaptabilidad & .67 & .72 & .74 & .72 \\
Manejo del estrés & .65 & .62 & .70 & .67 \\
C.E. total & .66 & .72 & .70 & .77 \\
Mujeres & & & & \\
Intrapersonal & .27 & .46 & .47 & .58 \\
Interpersonal & .50 & .60 & .59 & .58 \\
Adaptabilidad & .65 & .70 & .72 & .80 \\
Manejo del estrés & .66 & .72 & .72 & .71 \\
C.E. total & .64 & .73 & .73 & .73 \\
& & & &
\end{tabular}


Tabla 22

Coeficiente de consistencia interna para las escalas del BarOn ICE: NA - Forma completa (por grupos de edad y gestión)

\begin{tabular}{lcccc}
\hline $\begin{array}{l}\text { Gestión } \\
\quad \text { Escalas del } \\
\text { BarOn ICE: NA }\end{array}$ & $\begin{array}{c}10 \mathrm{a} 9 \\
\text { años }\end{array}$ & $\begin{array}{c}12 \\
\text { años }\end{array}$ & $\begin{array}{c}15 \\
\text { años }\end{array}$ & $\begin{array}{c}16 \text { a } \\
\text { años }\end{array}$ \\
\hline Estatal & & & & \\
$\quad$ Intrapersonal & .20 & .27 & .34 & .49 \\
Interpersonal & .55 & .66 & .71 & .68 \\
Adaptabilidad & .63 & .64 & .72 & .75 \\
Manejo del estrés & .43 & .49 & .54 & .55 \\
C.E. total & .62 & .73 & .78 & .78 \\
Estado de ánimo general & .67 & .76 & .75 & .78 \\
& & & & \\
Particular & & & & \\
Intrapersonal & .26 & .57 & .69 & .76 \\
Interpersonal & .67 & .68 & .72 & .75 \\
Adaptabilidad & .69 & .73 & .78 & .80 \\
Manejo del estrés & .57 & .63 & .70 & .73 \\
C.E. total & .73 & .79 & .80 & .82 \\
Estado de ánimo general & .70 & .79 & .81 & .84 \\
\hline
\end{tabular}

coeficientes de confiabilidad para la forma abreviada.

En las tablas 22 y 23 se presentan los coeficientes de consistencia interna considerando la gestión (colegios estatales y privados), observándose una mayor homogeneidad de los ítems dentro de cada escala. Además se puede apreciar que conforme se incrementa la edad, los coeficientes se incrementan.

En general, los coeficientes de confiabilidad son bastante satisfactorios a través de los diferentes grupos normativos, a pesar de que algunas escalas contienen poco número de ítems.

\section{Media de las correlaciones inter-ítems}

La media de las correlaciones interítems es otro indicador del grado en que los ítems de una escala particular
Tabla 23

Coeficiente de consistencia interna para las escalas del BarOn ICE: NA - Forma abreviada (por grupos de edad y gestión)

\begin{tabular}{lcccc}
\hline $\begin{array}{l}\text { Gestión } \\
\quad \text { Escalas del }\end{array}$ & $\begin{array}{c}10 \mathrm{a} 9 \\
12\end{array}$ & $\begin{array}{c}13 \mathrm{a} \\
15\end{array}$ & $\begin{array}{c}16 \mathrm{a} \\
18\end{array}$ \\
BarOn ICE: NA & años & años & años & años \\
\hline Estatal & & & & \\
$\quad$ Intrapersonal & .20 & .27 & .34 & .49 \\
Interpersonal & .48 & .57 & .58 & .60 \\
Adaptabilidad & .57 & .59 & .65 & .70 \\
Manejo del estrés & .56 & .63 & .69 & .66 \\
C.E. total & .52 & .64 & .64 & .69 \\
& & & & \\
Particular & & & & \\
Intrapersonal & .26 & .57 & .69 & .76 \\
Interpersonal & .56 & .59 & .65 & .68 \\
Adaptabilidad & .61 & .70 & .72 & .75 \\
Manejo del estrés & .71 & .70 & .76 & .81 \\
C.E. total & .61 & .72 & .71 & .77 \\
& & & & \\
\hline
\end{tabular}

miden consistentemente el mismo constructo. Las tablas 24 y 25 presentan las medias de las correlaciones inter-ítems para las diferentes escalas del BarOn ICE: NA, formas completa y abreviada, considerando los grupos de edad y sexo (excepto para el Índice de inconsistencia y la Escala de impresión positiva por las razones antes expuestas), y en las tablas 26 y 27 se presentan los mismos hallazgos, considerando los grupos de edad y gestión. En ellas se aprecia que las medias de las correlaciones inter-ítems ofrecen un patrón similar a través de los diversos grupos normativos. La magnitud de estas correlaciones brindan un soporte adicional para la consistencia interna de las escalas del inventario, mejorando con el incremento de edad. 
Tabla 24

Correlaciones inter-ítems para las escalas del BarOn ICE: NA - Forma completa (por grupos de edad y sexo)

\begin{tabular}{lcccc}
\hline $\begin{array}{l}\text { Sexo } \\
\begin{array}{c}\text { Escalas del } \\
\text { BarOn ICE: NA }\end{array}\end{array}$ & $\begin{array}{c}10 \text { a } 9 \\
\text { años }\end{array}$ & $\begin{array}{c}12 \\
\text { años }\end{array}$ & $\begin{array}{c}13 \text { a } \\
\text { años }\end{array}$ & $\begin{array}{c}16 \text { a } \\
18 \\
\text { años }\end{array}$ \\
\hline $\begin{array}{l}\text { Varones } \\
\text { Intrapersonal }\end{array}$ & .05 & .11 & .14 & .18 \\
Interpersonal & .15 & .16 & .18 & .16 \\
$\quad \begin{array}{l}\text { Adaptabilidad } \\
\text { Manejo del estrés }\end{array}$ & .20 & .20 & .23 & .22 \\
C. E. Total & .12 & .12 & .15 & .16 \\
Estado de ánimo general & .16 & .22 & .21 & .22 \\
& .09 & .10 & .10 & .11 \\
Mujeres & & & & \\
Intrapersonal & & & & \\
Interpersonal & .06 & .13 & .13 & .19 \\
Adaptabilidad & .15 & .16 & .18 & .18 \\
Manejo del estrés & .18 & .20 & .24 & .29 \\
C. E. Total & .12 & .17 & .15 & .14 \\
Estado de ánimo general & .16 & .20 & .20 & .23 \\
& .08 & .10 & .11 & .11 \\
& & & & \\
\hline
\end{tabular}

Tabla 26

Correlaciones inter-ítems para las escalas del BarOn ICE: NA - Forma completa (por grupos de edad y gestión)

\begin{tabular}{lcccc}
\hline $\begin{array}{l}\text { Sexo } \\
\begin{array}{l}\text { Escalas del } \\
\text { BarOn ICE: NA }\end{array}\end{array}$ & $\begin{array}{c}10 \text { a } \\
12\end{array}$ & $\begin{array}{c}13 \text { a } \\
15\end{array}$ & $\begin{array}{c}16 \text { a } \\
18 \\
\text { años }\end{array}$ & $\begin{array}{c}\text { años } \\
\text { años }\end{array}$ \\
\hline Estatal & & & & \\
$\quad$ Intrapersonal & .04 & .06 & .09 & .14 \\
Interpersonal & .09 & .14 & .14 & .16 \\
Adaptabilidad & .09 & .11 & .11 & .13 \\
Manejo del estrés & .15 & .16 & .16 & .23 \\
C. E. Total & .13 & .20 & .20 & .21 \\
Estado de ánimo general & .41 & .07 & .07 & .08 \\
& & & & \\
Particular & & & & .34 \\
Intrapersonal & .06 & .19 & .28 & .34 \\
Interpersonal & .14 & .15 & .17 & .20 \\
Adaptabilidad & .14 & .18 & .22 & .24 \\
Manejo del estrés & .18 & .23 & .27 & .29 \\
C. E. Total & .15 & .21 & .23 & .28 \\
Estado de ánimo general & .07 & .09 & .09 & .10 \\
& & & & \\
\hline
\end{tabular}

Tabla 25

Correlaciones inter-ítems para las escalas del BarOn ICE: NA - Forma abreviada (por grupos de edad y sexo)

\begin{tabular}{|c|c|c|c|c|}
\hline $\begin{array}{l}\text { Sexo } \\
\text { Escalas del } \\
\text { BarOn ICE: NA }\end{array}$ & $\begin{array}{l}7 \text { a } 9 \\
\text { años }\end{array}$ & $\begin{array}{c}10 \text { a } \\
12 \\
\text { años }\end{array}$ & $\begin{array}{c}13 \text { a } \\
15 \\
\text { años }\end{array}$ & $\begin{array}{c}16 \text { a } \\
18 \\
\text { años }\end{array}$ \\
\hline \multicolumn{5}{|l|}{ Varones } \\
\hline Intrapersonal & .05 & .11 & .14 & .18 \\
\hline Interpersonal & .18 & .18 & .19 & .18 \\
\hline Adaptabilidad & .25 & .30 & .32 & .30 \\
\hline Manejo del estrés & .24 & .22 & .29 & .25 \\
\hline C. E. total & .07 & .09 & .08 & .10 \\
\hline \multicolumn{5}{|l|}{ Mujeres } \\
\hline Intrapersonal & .06 & .13 & .13 & .19 \\
\hline Interpersonal & .14 & .20 & .19 & .18 \\
\hline Adaptabilidad & .24 & .28 & .30 & .40 \\
\hline Manejo del estrés & .25 & .30 & .29 & .29 \\
\hline C. E. total & .06 & .09 & .08 & .09 \\
\hline
\end{tabular}

Tabla 27

Correlaciones inter-ítems para las escalas del BarOn ICE: NA - Forma abreviada (por grupos de edad y gestión)

\begin{tabular}{|c|c|c|c|c|}
\hline $\begin{array}{l}\text { Sexo } \\
\text { Escalas del } \\
\text { BarOn ICE: NA }\end{array}$ & $\begin{array}{l}7 \text { a } 9 \\
\text { años }\end{array}$ & $\begin{array}{c}10 \text { a } \\
12 \\
\text { años }\end{array}$ & $\begin{array}{c}13 \text { a } \\
15 \\
\text { años }\end{array}$ & $\begin{array}{c}16 \text { a } \\
18 \\
\text { años } \\
\end{array}$ \\
\hline \multicolumn{5}{|l|}{ Estatal } \\
\hline Intrapersonal & .04 & .06 & .09 & .14 \\
\hline Interpersonal & .13 & .18 & .19 & .19 \\
\hline Adaptabilidad & .21 & .23 & .27 & .32 \\
\hline Manejo del estrés & .17 & .22 & .27 & .25 \\
\hline C. E. total & .05 & .08 & .07 & .09 \\
\hline \multicolumn{5}{|l|}{ Particular } \\
\hline Intrapersonal & .06 & .19 & .28 & .34 \\
\hline Interpersonal & .18 & .19 & .24 & .25 \\
\hline Adaptabilidad & .24 & .32 & .34 & .38 \\
\hline Manejo del estrés & .29 & .28 & .35 & .42 \\
\hline C. E. total & .07 & .10 & .10 & .13 \\
\hline
\end{tabular}




\section{Error estándar}

En la tabla 28 se presentan tres tipos de error estándar para el BarON ICE: NA calculados con los resultados de la muestra peruana. Cada uno de ellos tiene diferentes significados e interpretaciones.

El error estándar de la media estima el grado en que se esperaría que varíe la media en muestras diferentes del mismo tamaño extraídas de la misma población. Su valor depende del tamaño de la muestra obtenida y generalmente es muy pequeño, como ocurre con los datos de la tabla 28 , lo que re- velaría que las normas son estables. Indica las fluctuaciones alrededor del puntaje obtenido en el ICE: NA. Por ejemplo, en la escala Interpersonal en el grupo de varones de 16 a 18 años, con un 68 por ciento de confianza, se espera que el puntaje obtenido se encuentre en el intervalo \pm 0.40 , o con un 95 por ciento entre \pm 0.80

El error estándar de estimación (predicción) indica el grado de fluctuación que se esperaría entre los puntajes originales de los examinados y los puntajes del retest. Por ejemplo, el error estándar de estimación para la escala Interpersonal en el grupo de varones de 16 a 18

Tabla 28

Errores estándares del BarOn ICE: NA - Forma completa

\begin{tabular}{|c|c|c|c|c|c|c|c|}
\hline \multirow[b]{2}{*}{$\begin{array}{l}\text { Grupos } \\
\text { de edad }\end{array}$} & \multirow[b]{2}{*}{ Escalas } & \multicolumn{3}{|c|}{ Varones } & \multicolumn{3}{|c|}{ Mujeres } \\
\hline & & $\begin{array}{c}\text { EE de la } \\
\text { media }\end{array}$ & $\begin{array}{l}\text { EE de } \\
\text { medida }\end{array}$ & $\begin{array}{c}\text { EE de } \\
\text { estimación }\end{array}$ & $\begin{array}{c}\text { EE de la } \\
\text { media }\end{array}$ & $\begin{array}{l}\text { EE de } \\
\text { medida }\end{array}$ & $\begin{array}{c}\text { EE de } \\
\text { estimación }\end{array}$ \\
\hline \multirow{6}{*}{$\begin{array}{l}7 \text { a } 9 \\
\text { años }\end{array}$} & Intrapersonal & 0.14 & 2.92 & 3.24 & 0.14 & 2.86 & 3.23 \\
\hline & Interpersonal & 0.26 & 3.47 & 4.52 & 0.26 & 3.41 & 4.09 \\
\hline & Adaptabilidad & 0.25 & 3.17 & 4.14 & 0.24 & 3.13 & 4.07 \\
\hline & Manejo del estrés & 0.26 & 3.85 & 4.90 & 0.27 & 3.83 & 4.88 \\
\hline & C.E. total & 0.30 & 3.84 & 5.01 & 0.28 & 3.58 & 4.67 \\
\hline & Estado de ánimo en general & 0.28 & 2.66 & 3.61 & 0.27 & 2.67 & 3.61 \\
\hline \multirow{6}{*}{$\begin{array}{c}10 \text { a } 12 \\
\text { años }\end{array}$} & Intrapersonal & 0.13 & 2.46 & 2.92 & 0.15 & 2.44 & 2.95 \\
\hline & Interpersonal & 0.24 & 3.23 & 4.19 & 0.24 & 2.95 & 3.85 \\
\hline & Adaptabilidad & 0.22 & 2.77 & 3.62 & 0.22 & 2.66 & 3.47 \\
\hline & Manejo del estrés & 0.23 & 3.38 & 4.31 & 0.27 & 3.20 & 4.18 \\
\hline & C.E. total & 0.27 & 3.10 & 4.13 & 0.29 & 3.19 & 4.23 \\
\hline & Estado de ánimo en general & 0.29 & 2.53 & 3.45 & 0.30 & 2.46 & 3.35 \\
\hline \multirow{6}{*}{$\begin{array}{c}13 \text { a } 15 \\
\text { años }\end{array}$} & Intrapersonal & 0.14 & 2.24 & 2.71 & 0.16 & 2.32 & 2.82 \\
\hline & Interpersonal & 0.25 & 2.89 & 3.80 & 0.29 & 2.90 & 3.81 \\
\hline & Adaptabilidad & 0.23 & 2.52 & 3.33 & 0.26 & 2.52 & 3.34 \\
\hline & Manejo del estrés & 0.24 & 3.04 & 3.94 & 0.29 & 3.17 & 4.80 \\
\hline & C.E. total & 0.28 & 2.96 & 3.94 & 0.34 & 3.44 & 4.52 \\
\hline & Estado de ánimo en general & 0.29 & 2.31 & 3.16 & 0.36 & 2.56 & 3.51 \\
\hline \multirow{6}{*}{$\begin{array}{c}16 \text { a } 18 \\
\text { años }\end{array}$} & Intrapersonal & 0.25 & 2.20 & 2.74 & 0.27 & 2.27 & 2.86 \\
\hline & Interpersonal & 0.40 & 2.91 & 3.79 & 0.41 & 2.91 & 3.80 \\
\hline & Adaptabilidad & 0.35 & 2.42 & 3.18 & 0.40 & 2.33 & 4.18 \\
\hline & Manejo del estrés & 0.39 & 2.89 & 3.76 & 0.41 & 3.08 & 4.63 \\
\hline & C.E. total & 0.48 & 3.05 & 4.07 & 0.49 & 2.95 & 3.94 \\
\hline & Estado de ánimo en general & 0.49 & 2.28 & 3.13 & 0.55 & 2.64 & 3.60 \\
\hline
\end{tabular}


Tabla 29

Errores estándares del BarOn ICE: NA - Forma abreviada

\begin{tabular}{|c|c|c|c|c|c|c|c|}
\hline $\begin{array}{l}\text { Grupos } \\
\text { de Edad }\end{array}$ & Escalas & $\begin{array}{c}\text { EE de } \\
\text { la } \\
\text { media }\end{array}$ & $\begin{array}{l}\text { Varone } \\
\text { EE de } \\
\text { medida }\end{array}$ & $\begin{array}{c}\text { EE de } \\
\text { Estimación }\end{array}$ & $\begin{array}{c}\text { EE de } \\
\text { la } \\
\text { media }\end{array}$ & $\begin{array}{l}\text { Mujeres } \\
\text { EE de } \\
\text { medida }\end{array}$ & $\begin{array}{c}\text { EE de } \\
\text { Estimación }\end{array}$ \\
\hline 7 a 9 & Intrapersonal & 0.14 & 2.92 & 3.24 & 0.14 & 2.86 & 3.23 \\
\hline \multirow[t]{4}{*}{ años } & Interpersonal & 0.16 & 2.40 & 3.02 & 0.14 & 2.36 & 2.89 \\
\hline & Adaptabilidad & 0.17 & 2.30 & 2.98 & 0.16 & 2.27 & 2.91 \\
\hline & Manejo del estrés & 0.18 & 2.53 & 3.25 & 0.19 & 2.52 & 3.25 \\
\hline & C.E. total & 0.39 & 5.35 & 6.90 & 0.36 & 5.09 & 6.52 \\
\hline \multirow{5}{*}{$\begin{array}{c}10 \text { a } 12 \\
\text { años }\end{array}$} & Intrapersonal & 0.13 & 2.46 & 2.92 & 0.15 & 2.44 & 2.95 \\
\hline & Interpersonal & 0.14 & 2.11 & 2.66 & 0.14 & 1.99 & 2.52 \\
\hline & Adaptabilid ad & 0.15 & 1.91 & 2.51 & 0.15 & 1.85 & 2.41 \\
\hline & Manejo del estrés & 0.16 & 2.28 & 2.90 & 0.18 & 2.07 & 2.72 \\
\hline & C.E. total & 0.36 & 4.53 & 5.95 & 0.39 & 4.50 & 5.92 \\
\hline 13 a 15 & Intrapersonal & 0.14 & 2.24 & 2.71 & 0.16 & 2.32 & 2.82 \\
\hline \multirow[t]{4}{*}{ Años } & Interpersonal & 0.14 & 1.99 & 2.50 & 0.16 & 1.97 & 2.49 \\
\hline & Adaptabilidad & 0.15 & 1.72 & 2.27 & 0.18 & 1.85 & 2.42 \\
\hline & Manejo del estrés & 0.16 & 1.97 & 2.56 & 0.19 & 1.96 & 2.57 \\
\hline & C.E. total & 0.35 & 4.23 & 5.52 & 0.41 & 4.20 & 5.53 \\
\hline 16 a 18 & Intrapersonal & 0.25 & 2.20 & 2.74 & 0.27 & 2.27 & 2.86 \\
\hline \multirow[t]{4}{*}{ Años } & Interpersonal & 0.23 & 2.00 & 2.51 & 0.22 & 1.58 & 2.07 \\
\hline & Adaptabilidad & 0.24 & 1.71 & 2.25 & 0.28 & 1.63 & 2.19 \\
\hline & Manejo del estrés & 0.24 & 1.85 & 2.39 & 0.28 & 2.14 & 2.76 \\
\hline & C.E. total & 0.63 & 4.10 & 5.45 & 0.61 & 3.71 & 4.96 \\
\hline
\end{tabular}

años es 3.79. Este valor significaría que si un grupo grande de personas fuese sometido a un retest, el 68 por ciento tendría resultados que se encontrarían dentro de un error estándar de $( \pm 3.79)$ y el 95 por ciento dentro de dos errores estándares ( \pm 7.58).

Así mismo, en la tabla 29 se presentan los errores estándares para la forma abreviada del inventario.

\section{VALIDEZ DE CONSTRUCTO}

\section{Estructura factorial del BarOn ICE: NA}

La evaluación de la estructura factorial de un instrumento permite a los usuarios potenciales determinar si los factores tienen sentido conceptualmente. De allí que este tipo de análisis (análisis factorial) es particularmente relevante para la validación del constructo. Esta sección examina la estructura factorial de las formas completa y abreviada del BarOn ICE: NA. El primer enfoque resume el trabajo analítico factorial que involucra la aplicación de procedimientos estadísticos para examinar la estructura del inventario. Un segundo enfoque examina las intercorrelaciones entre las escalas para ver si reúnen las expectativas teóricas.

La estructura factorial de los 40 ítemes de las escalas intrapersonal, interpersonal, manejo del estrés y adaptabilidad fueron examinadas mediante un análisis factorial exploratorio en una muestra normativa peruana de niños y 
adolescentes de Lima metropolitana $(\mathrm{N}$ = 3374). Se utilizó un análisis de los componentes principales con una rotación Varimax. La tabla 30 presenta los 40 ítems analizados que facilitarán la lectura de las tablas 31 y 32 donde se muestran los pesos factoriales rotados, eigenvalues y porcentaje de varianza explicada para cada uno de los factores

Figura 1

Representación de las varianzas explicadas en cada factor del BarOn ICE: NA - Versión completa para la muestra total y las submuestras

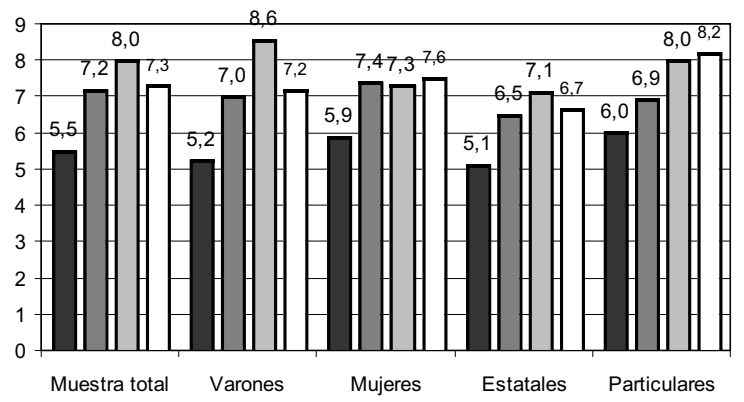

Intrapersonal $\square$ Interpersonal $\quad$ Adaptabilidad $\mathbf{Q}$ Manejo del estrés

Figura 2

Representación de las varianzas explicadas en cada factor del BarOn ICE: NA - Versión abreviada para la muestra total y submuestras

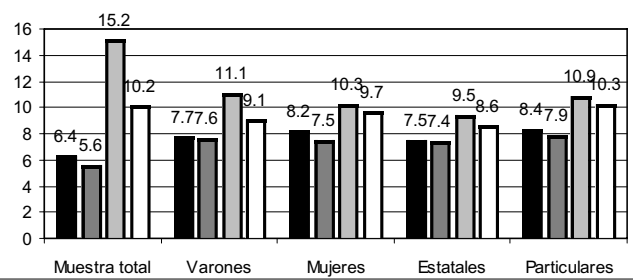

Intrapersonal $\square$ Interpersonal $\square$ Adaptabilidad $\square$ Manejo del estrés de este análisis factorial exploratorio para la muestra total y las submuestras según sexo y gestión, tanto para la forma completa como para la abreviada. Las figuras 1 y 2 representan las varianzas explicadas para cada factor. $\mathrm{La}$ solución factorial dio lugar a cuatro factores empíricos que corresponden a las cuatro escalas del BarOn ICE: NA:

Para la muestra total, en la versión completa (tabla 31), se hallaron como factores más importantes la escala de adaptabilidad, seguida del manejo del estrés y del interpersonal; el más bajo fue la escala intrapersonal. En la submuestra de varones, el factor más relevante fue la adaptabilidad y los demás factores son similares al de la muestra total. En el grupo de mujeres los factores interpersonal, adaptabilidad y manejo del estrés tiene una varianza explicada semejante, siendo también muy bajo el intrapersonal. En la submuestra de estatales destaca el factor adaptabilidad, seguido del manejo del estrés y el interpersonal; el más bajo es el intrapersonal; y en los particulares los factores manejo del estrés y adaptabilidad son los más elevados, luego le sigue el interpersonal y por último el intrapersonal.

Para la muestra total, en la versión abreviada (tabla 32), destaca el factor de adaptabilidad, seguido del manejo del estrés, el intrapersonal y el interpersonal. En las sub- 
Tabla 30

\section{Ítems analizados factorialmente}

\footnotetext{
2 Soy muy bueno (a) para comprender cómo la gente se siente

3 Puedo mantener la calma cuando estoy molesto

5 Me importa lo que les sucede a las personas

6 Me es difícil controlar mi cólera

7 Es fácil decirle a la gente cómo me siento

10 Sé cómo se sienten las personas

11 Sé cómo mantenerme tranquilo

12 Intento usar diferentes formas de responder las preguntas difíciles

14 Soy capaz de respetar a los demás

15 Me molesto demasiado de cualquier cosa

16 Es fácil para mí comprender las cosas nuevas

17 Puedo hablar fácilmente sobre mis sentimientos

20 Tener amigos es importante

21 Peleo con la gente

22 Puedo comprender preguntas difíciles

24 Intento no herir los sentimientos de las personas

25 No me doy por vencido(a) ante un problema hasta que lo resuelvo

26 Tengo mal genio

28 Es difícil hablar sobre mis sentimientos más íntimos

30 Puedo dar buenas respuestas a preguntas difíciles

31 Puedo fácilmente describir mis sentimientos

34 Puedo tener muchas maneras de responder una pregunta difícil, cuando yo quiero
}

$35 \mathrm{Me}$ molesto fácilmente

$36 \mathrm{Me}$ agrada hacer las cosas para los demás

38 Puedo usar fácilmente diversos modos de resolver los problemas

39 Demoro en molestarme

41 Hago amigos fácilmente

43 Para mí es fácil decirle a las personas cómo me siento

44 Cuando respondo preguntas difíciles trato de pensar en muchas soluciones

$45 \mathrm{Me}$ siento mal cuando las personas son heridas en sus sentimientos

46 Cuando estoy molesto (a) con alguien, me siento molesto (a) por mucho tiempo

48 Soy bueno (a) resolviendo problemas

49 Para mí es difícil esperar mi turno

$51 \mathrm{Me}$ agradan mis amigos

53 Me es difícil decirle a los demás mis sentimientos

54 Me disgusto fácilmente

55 Puedo darme cuenta cuando mi amigo se siente triste

57 Aun cuando las cosas sean difíciles, no me doy por vencido

58 Cuando me molesto actúo sin pensar

59 Sé cuándo la gente está molesta aun cuando no dicen nada muestras de varones, mujeres, estatales y particulares, los factores se presentan en el mismo sentido que en la muestra total.

\section{INTERCORRELACIONES DE LAS ESCALAS DEL BARON ICE: NA}

Las tablas 33, 34, 35 y 36 presentan las intercorrelaciones entre las escalas para las formas completa y abreviada, separadamente, por sexo y gestión. Los datos para ambas tablas se basaron en la muestra normativa anteriormente descrita.
Dado que el instrumento mide distintos aspectos de la inteligencia emocional, las correlaciones fueron de bajas a moderadas entre las diferentes escalas: intrapersonal, interpersonal, manejo del estrés y adaptabilidad.

\section{Correlaciones entre las formas completa y abreviada}

Las tablas 37 y 38 presentan las correlaciones entre las versiones completa y abreviada del BarOn ICE: NA según sexo y gestión, respectivamente, basándose en la muestra normativa. 
Tabla 31

Pesos de los ítems en el análisis factorial exploratorio (cuatro factores rotados) del BarOn ICE: NA - Forma completa para la muestra total $(\mathbf{N}=3374)$, sexo $($ varones $=1793$, mujeres $=1581)$, gestión $($ estatal $=1858$, particular $=1516)$

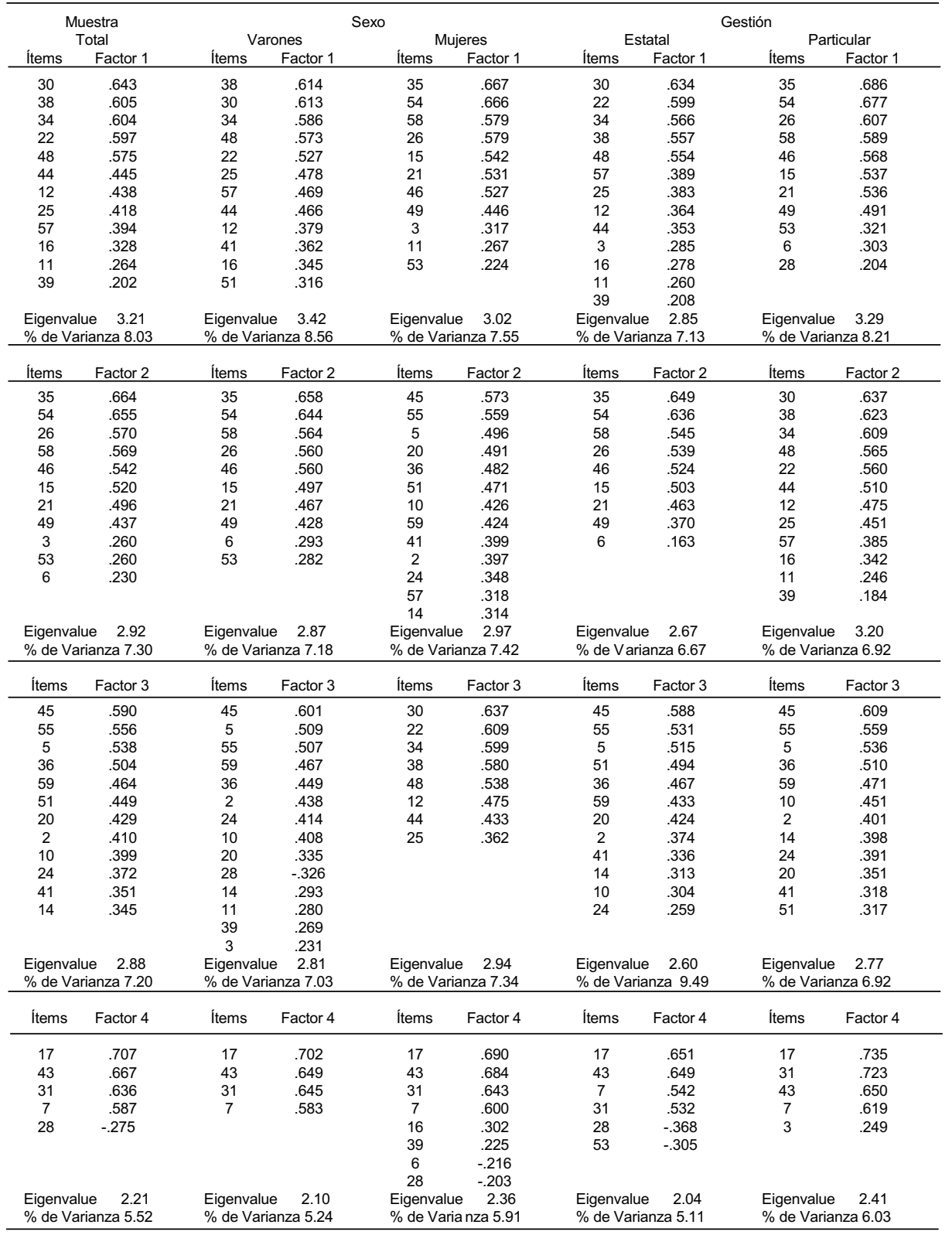

Método de extracción: Análisis de los componentes principales.

Método de rotación: Varimax con normalización Kaiser.

Rotación convergió en 6 iteraciones. 
Tabla 32

Pesos de los ítems en el análisis factorial exploratorio (cuatro factores rotados) del BarOn ICE: NA - Forma abreviada para la muestra total $(\mathrm{N}=3374)$, sexo (varones = 1793 , mujeres $=1581)$, gestión $($ estatal $=1858$, particular $=1516)$

\begin{tabular}{|c|c|c|c|c|c|c|c|c|c|}
\hline \multirow{2}{*}{\multicolumn{2}{|c|}{$\begin{array}{c}\text { Muestra } \\
\text { Total }\end{array}$}} & \multirow{2}{*}{\multicolumn{4}{|c|}{ Sexo }} & \multicolumn{4}{|c|}{ Gestión } \\
\hline & & & & & & \multicolumn{2}{|c|}{ Estatal } & \multicolumn{2}{|c|}{ Particular } \\
\hline Ítems & Factor 1 & Ítems & Factor 1 & Ítems & Factor 1 & Ítems & Factor 1 & Ítems & Factor 1 \\
\hline 30 & .686 & 38 & .657 & 30 & .650 & 30 & .675 & 30 & .651 \\
\hline 22 & .649 & 30 & .654 & 22 & .648 & 22 & .661 & 38 & .651 \\
\hline 38 & .642 & 48 & .625 & 34 & .616 & 48 & .592 & 34 & .629 \\
\hline 48 & .629 & 22 & .607 & 38 & .599 & 38 & .585 & 22 & .610 \\
\hline 34 & .612 & 34 & .600 & 48 & .578 & 34 & .569 & 48 & .588 \\
\hline \multirow[t]{3}{*}{44} & .458 & 44 & .491 & 12 & .505 & 12 & .413 & 12 & .505 \\
\hline & & 12 & .442 & 44 & .451 & 44 & .389 & 44 & .501 \\
\hline & & 16 & .358 & & & 16 & .260 & 16 & .357 \\
\hline \multirow{2}{*}{\multicolumn{2}{|c|}{$\begin{array}{lr}\text { Eigenvalue } & 3.65 \\
\% \text { de Varianza } 15.2 \\
\end{array}$}} & \multirow{2}{*}{\multicolumn{2}{|c|}{$\begin{array}{lr}\text { Eigenvalue } \quad 2.88 \\
\% \text { de Varianza } 11.1 \\
\end{array}$}} & \multirow{2}{*}{\multicolumn{2}{|c|}{$\begin{array}{lr}\text { Eigenvalue } & 2.68 \\
\% \text { de Varianza } & 10.3 \\
\end{array}$}} & \multirow{2}{*}{\multicolumn{2}{|c|}{$\begin{array}{l}\text { Eigenvalue } 2.46 \\
\text { \% de Varianza } 9.5 \\
\end{array}$}} & \multirow{2}{*}{\multicolumn{2}{|c|}{$\begin{array}{l}\text { Eigenvalue } \quad 3.29 \\
\% \text { de Varianza } 8.21\end{array}$}} \\
\hline & & & & & & & & & \\
\hline Ítems & Factor 2 & Ítems & Factor 2 & Ítems & Factor 2 & Ítems & Factor 2 & Ítems & Factor 2 \\
\hline 35 & .702 & 35 & .708 & 35 & .689 & 35 & .680 & 35 & .729 \\
\hline 54 & .658 & 54 & .643 & 54 & .674 & 54 & .629 & 54 & .683 \\
\hline 26 & .618 & 26 & .602 & 26 & .635 & 26 & .590 & 26 & .652 \\
\hline 58 & .570 & 58 & .556 & 58 & .584 & 58 & .558 & 15 & .589 \\
\hline 15 & .563 & 15 & .546 & 15 & .583 & 15 & .541 & 58 & .575 \\
\hline 21 & .524 & 21 & .507 & 21 & .554 & 21 & .498 & 21 & .558 \\
\hline \multirow[t]{2}{*}{53} & .271 & 53 & .268 & 53 & .246 & & & 53 & .339 \\
\hline & & & & 28 & .203 & & & & \\
\hline & \multirow{2}{*}{\multicolumn{2}{|c|}{$\%$ de Varianza 9.1}} & Eigenvalue & 2.51 & Eigenvalue & 2.24 & Eigenvalue & 2.82 \\
\hline \multicolumn{2}{|c|}{$\%$ de Varianza 10.2} & & & \multicolumn{2}{|c|}{ \% de Varianza 9.6} & \multicolumn{2}{|c|}{$\%$ de Varianza 8.6} & \multicolumn{2}{|c|}{$\%$ de Varianza 10.9} \\
\hline Ítems & Factor 3 & Ítems & Factor 3 & \multicolumn{2}{|c|}{ Ítems Factor 3} & Ítems & Factor 3 & Ítems & Factor 3 \\
\hline 17 & .726 & 17 & .717 & 17 & .721 & 43 & .680 & 31 & .756 \\
\hline 43 & .693 & 43 & .677 & 43 & .700 & 17 & .672 & 17 & .755 \\
\hline 31 & .671 & 31 & .669 & 31 & .673 & 31 & .580 & 43 & .693 \\
\hline 7 & .619 & 7 & .607 & 7 & .622 & 7 & .561 & 7 & .648 \\
\hline 28 & -.253 & & & 16 & .293 & 28 & -.352 & & \\
\hline & & & & & & 53 & -.287 & & \\
\hline Eigenval & 1.53 & Eigenvalue & 2.81 & Eigenvalue & 2.14 & Eigenvalue & 1.95 & Eigenvalue & 2.67 \\
\hline$\%$ de Var & anza 6.3 & $\%$ de Varia & anza 7.03 & $\%$ de Varia & anza 8.2 & $\%$ de Varia & anza 7.5 & $\%$ de Varia & nza 10.3 \\
\hline Ítems & Factor 4 & Ítems & Factor 4 & Ítems & Factor 4 & Ítems & Factor 4 & Ítems & Factor 4 \\
\hline 45 & .666 & 45 & .675 & 45 & .666 & 45 & .660 & 45 & .663 \\
\hline 45 & .577 & 5 & .548 & 55 & .606 & 55 & .581 & 36 & .601 \\
\hline 55 & .566 & 36 & .520 & 36 & .534 & 5 & .529 & 5 & .575 \\
\hline 5 & .562 & 55 & .520 & 5 & .520 & 59 & .490 & 55 & .563 \\
\hline 36 & .495 & 59 & .506 & 59 & .437 & 36 & .487 & 59 & .490 \\
\hline 59 & .383 & 28 & -.336 & 14 & .367 & 14 & .344 & 14 & .381 \\
\hline 14 & & 14 & .286 & & & & & 28 & -.281 \\
\hline Eigenvalı & $\quad 1.35$ & Eigenvalue & $\quad 1.97$ & Eigenvalue & 1.96 & Eigenvalue & 1.92 & Eigenvalue & 2.06 \\
\hline$\%$ de Var & anza 5.6 & $\%$ de Varia & anza 7.6 & $\%$ de Varia & anza 7.52 & $\%$ de Varia & anza 7.4 & $\%$ de Varia & nza 7.9 \\
\hline
\end{tabular}

Método de extracción: Análisis de componentes principales.

Método de rotación: Varimax con normalización Kaiser.

Rotación convergió en 5 o 6 iteraciones. 
Tabla 33

Intercorrelaciones de las escalas BarOn ICE: NA - Forma completa por sexo

\begin{tabular}{|c|c|c|c|c|c|c|}
\hline Escalas & 1 & 2 & 3 & 4 & 5 & 6 \\
\hline 1. Intrapersonal & & $.22^{\star \star}$ & $.25^{\star \star}$ & $.09^{* *}$ & $.62^{\star \star}$ & $.23^{\star *}$ \\
\hline 2. Interpersonal & $.22^{\star \star}$ & & $.54^{\star \star}$ & $.15^{\star \star}$ & $.73^{\star \star}$ & $.59^{\star \star}$ \\
\hline 3. Adaptabilidad & $.24^{\star \star}$ & $.52^{* *}$ & & $.10^{* *}$ & $.74^{\star \star}$ & $.57^{\star \star}$ \\
\hline 4. Manejo del estrés & $.08^{\star \star}$ & $.15^{\star \star}$ & $.08^{\star \star}$ & & $.49^{\star \star}$ & $.26^{\star \star}$ \\
\hline 5. CE total & $.63^{\star \star}$ & $.72^{\star \star}$ & $.72^{\star \star}$ & $.49^{* *}$ & & $.64^{* *}$ \\
\hline 6. Estado de A. G. & $.26^{\star \star}$ & $.52^{* \star}$ & $.51^{\star \star}$ & $.20^{* *}$ & $.58^{\star \star}$ & \\
\hline
\end{tabular}

Nota: Varones $(n=1793)$ están arriba de la diagonal y Mujeres $(n=$ 1581) están debajo de la diagonal. (CE total = cociente emocional total; Estado de A.G. = Estado de ánimo general).

${ }^{* *} p<.01$

Tabla 35

Intercorrelaciones de las escalas BarOn ICE: NA - Forma completa por gestión

\begin{tabular}{|c|c|c|c|c|c|c|}
\hline Escalas & 1 & 2 & 3 & 4 & 5 & 6 \\
\hline 1. Intrapersonal & & $.17^{\star *}$ & $.21^{\star *}$ & $.06^{* *}$ & $.59^{* *}$ & $.20^{* *}$ \\
\hline 2. Interpersonal & $.23^{\star *}$ & & $.48^{* *}$ & $.11^{\star *}$ & $.70^{* *}$ & $.52^{* *}$ \\
\hline 3. Adaptabilidad & $.26^{\star *}$ & $.41^{* *}$ & & $.06^{* *}$ & $.72^{\star *}$ & $.51^{* *}$ \\
\hline 4. Manejo del estrés & $.09^{* *}$ & $.15^{\star *}$ & $.07^{* *}$ & & $.47^{\star *}$ & $.19^{* *}$ \\
\hline 5. CE total & $.68^{* *}$ & $.66^{\star *}$ & $.67^{* *}$ & $.52^{* *}$ & & $.57^{* *}$ \\
\hline 6. Estado de A. G. & $.29^{* *}$ & $.44^{* *}$ & $.46^{* *}$ & $.27^{\star *}$ & $.56^{\star *}$ & \\
\hline
\end{tabular}

Nota: Estatal $(n=1858)$ están arriba de la diagonal y Particular $(n=$ 1516) están debajo de la diagonal. $\mathrm{CE}$ total = Cociente emocional total; Estado de ánimo general).

${ }^{\star *} p<.01$

Las correlaciones de cada una de las escalas con el cociente emocional total va desde baja .37 a elevada .94 , pero todas ellas son significativas al uno por ciento. El estado de ánimo general es un factor motivacional muy importante y correlaciona moderadamente con el cociente emocional general tanto en varones como en mujeres, y en colegios estatales y particulares.

\section{Otras evidencias de validez}

Los datos de las tablas 39 y 40 se focalizan en dos aspectos: la relación entre el BarOn ICE: NA, versiones completa y
Tabla 34

Intercorrelaciones de las escalas BarOn ICE: NA - Forma abreviada por sexo

\begin{tabular}{lccccc}
\hline \multicolumn{1}{c}{ Escalas } & 1 & 2 & 3 & 4 & 5 \\
\hline 1. Intrapersonal & & $.16^{\star \star}$ & $.25^{\star \star}$ & $.06^{\star}$ & $.57^{\star \star}$ \\
2. Interpersonal & $.16^{\star \star}$ & & $.43^{\star \star}$ & $.07^{\star}$ & $.66^{\star \star}$ \\
3. Adaptabilidad & $.21^{\star \star}$ & $.37^{\star \star}$ & & .02 & $.71^{\star *}$ \\
4. Manejo del estrés & .05 & $.08^{\star \star}$ & .02 & & $.50^{\star \star}$ \\
5. CE total & $.57^{\star \star}$ & $.64^{\star \star}$ & $.66^{\star \star}$ & $.53^{\star \star}$ &
\end{tabular}

Nota: Varones $(n=1793)$ están arriba de la diagonal y Mujeres $(n=$ 1581) están debajo de la diagonal. (CE total = cociente emocional total). ${ }^{* *} p<.01$

${ }^{*} p<.05$

Tabla 36

Intercorrelaciones de las escalas BarOn ICE: NA - Forma abreviada por gestión

\begin{tabular}{|c|c|c|c|c|c|}
\hline Escalas & 1 & 2 & 3 & 4 & 5 \\
\hline 1. Intrapersonal & & $.11^{\star *}$ & $.19^{* *}$ & $.05^{*}$ & $.53^{* *}$ \\
\hline 2. Interpersonal & $.17^{\star *}$ & & $.37^{* *}$ & $.05^{*}$ & $.64^{* *}$ \\
\hline 3. Adaptabilidad & $.26^{\star *}$ & $.30^{\star *}$ & & .02 & $.68^{* *}$ \\
\hline 4. Manejo del estrés & .05 & $.07^{* *}$ & .01 & & $.51^{* *}$ \\
\hline 5. CE total & $.61^{* *}$ & $.60^{* *}$ & $.63^{* *}$ & $.54^{* *}$ & \\
\hline
\end{tabular}

Nota: Estatal $(n=1858$ ) están arriba de la diagonal y Particular ( $n=$ 1516) están debajo de la diagonal. CE total = Cociente emocional). ${ }^{* *} p<.01$

${ }^{*} p<.05$

abreviada con el I-CE de BarOn para adultos (Ugarriza, 2003) y la relación del BarOn ICE: NA según el sexo en una muestra de estudiantes universitarios del primer ciclo de una universidad particular. Por otro lado, las tablas $41 \mathrm{y}$ 42 reportan las correlaciones entre la Escala de Depresión de Reynolds para Niños y Adolescentes con el BarOn ICE: NA, versiones completa y abreviada en un centro educativo estatal de Viña Alta, en el distrito limeño de La Molina.

En la tabla 41, tanto en varones como en mujeres, existe una correlación inversa significativa $(-.36,-.70$, respec- 
Tabla 37

Correlaciones entre las formas completa y abreviada del BarOn ICE: NA según el sexo

\begin{tabular}{|c|c|c|c|c|c|}
\hline \multirow{2}{*}{$\begin{array}{l}\text { BarOn ICE: NA } \\
\text { Forma completa }\end{array}$} & \multicolumn{5}{|c|}{ BarOn ICE: NA Forma abreviada } \\
\hline & Intra. & Inter. & Adapt. & estrés & Total \\
\hline \multicolumn{6}{|l|}{ Varones $(\mathrm{N}=1793)$} \\
\hline Intrapersonal & 1.00 & $.16^{\star \star}$ & $.25^{\star \star}$ & $.06^{\star *}$ & $.57^{\star *}$ \\
\hline Interpersonal & $* *$ & $.87^{* *}$ & $.50^{\star *}$ & $.07^{* *}$ & $.67^{* *}$ \\
\hline Adaptabilida d & $.22^{* *}$ & $.46^{* *}$ & $.91^{* *}$ & $.02^{\star *}$ & $.67^{* *}$ \\
\hline Manejo del estrés & $.25^{\star *}$ & $.14^{\star *}$ & $.11^{* *}$ & $.89^{* *}$ & $.53^{* *}$ \\
\hline CE total & $.08^{* *}$ & $.62^{* *}$ & $.70^{* *}$ & $.37^{* *}$ & $.94^{* *}$ \\
\hline Estado de A. G. & $\begin{array}{l}.62^{\star *} \\
.23^{\star *}\end{array}$ & $.49^{* *}$ & $.54^{\star *}$ & $.18^{* *}$ & $.59^{* *}$ \\
\hline \multicolumn{6}{|l|}{ Mujeres $(N=1581)$} \\
\hline Intrapersonal & 1.00 & $.16^{* *}$ & $.21^{* *}$ & .05 & $.57^{\star \star}$ \\
\hline Interpersonal & $\star *$ & $.86^{\star *}$ & $.46^{\star *}$ & $.09^{\star \star}$ & $.65^{\star *}$ \\
\hline Adaptabilidad & $.22^{* *}$ & $.42^{\star *}$ & $.91^{* *}$ & -.00 & $.64^{* *}$ \\
\hline Manejo del estrés & $.24^{\star *}$ & $.12^{* *}$ & $.10^{\star *}$ & $.89^{* *}$ & $.54^{\star *}$ \\
\hline CE total & $.08^{* *}$ & $.59^{\star *}$ & $.66^{\star \star}$ & $.39^{* *}$ & $.94^{\star *}$ \\
\hline Estado de A. G. & $\begin{array}{l}.63^{* *} \\
.26^{* *}\end{array}$ & $.43^{* *}$ & $.51^{* *}$ & $.15^{* *}$ & $.56^{* *}$ \\
\hline
\end{tabular}

Nota: Intra = Intrapersonal; Inter = interpesonal; Adapt. = Adaptabilidad; estrés $=$ Manejo del estrés; Total $=$ Cociente emocional total; Estado de A.G. = Estado de ánimo general; $C E$ total = Cociente emocional total ${ }^{\star *} p<.01$

tivamente) entre el puntaje total de depresión y el de estado de ánimo general; además, existe una correlación negativa significativa entre depresión y adaptabilidad (-.42) en el grupo de mujeres. En la tabla 42 solo es significativa la correlación entre el puntaje total de la depresión y el manejo del estrés en el grupo de varones (.35), lo que expresaría que a mayor depresión mayor dificultad para el manejo del estrés.

\section{DISCUSIÓN}

La consistencia interna del ICE: NA, forma completa $\mathrm{y}$ abreviada, medida por el Alfa de Cronbach arroja resultados consistentes; varían desde bajos para el área intrapersonal para los niños de siete a nueve años; moderados para
Tabla 38

Correlaciones entre las formas completa y abreviada del BarOn ICE: NA según la gestión

\begin{tabular}{|c|c|c|c|c|c|}
\hline \multirow{2}{*}{$\begin{array}{l}\text { BarOn ICE: NA } \\
\text { Forma completa }\end{array}$} & \multicolumn{5}{|c|}{ BarOn ICE: NA de abreviada } \\
\hline & Intra. & Inter. & Adapt. & estrés & Total \\
\hline \multicolumn{6}{|l|}{ Estatal $(\mathrm{N}=1858)$} \\
\hline Intrapersonal & $1.00^{* *}$ & $.11^{* *}$ & $.19^{* *}$ & $.05^{*}$ & $.53^{\star *}$ \\
\hline Interpersonal & $.17^{\star *}$ & $.86^{* *}$ & $.43^{\star *}$ & $.05^{*}$ & $.63^{* *}$ \\
\hline Adaptabilidad & $.21^{* *}$ & $.40^{* *}$ & $.89^{\star *}$ & -.00 & $.64^{* *}$ \\
\hline Manejo del estrés & $.06^{* *}$ & $.10^{* *}$ & $.09^{\star *}$ & $.87^{\star *}$ & $.51^{* *}$ \\
\hline CE total & $.59^{* *}$ & $.59 * *$ & $.66^{\star *}$ & $.36^{* *}$ & $.93^{* *}$ \\
\hline Estado de A. G. & $.20^{* *}$ & $.43^{* *}$ & $.50^{\star *}$ & $.12^{* *}$ & $.53^{* *}$ \\
\hline \multicolumn{6}{|l|}{ Particular $(\mathrm{N}=1516)$} \\
\hline Intrapersonal & $1.00^{* *}$ & $.17^{* *}$ & $.26^{\star \star}$ & .05 & $.61^{\star *}$ \\
\hline Interpersonal & $.23^{\star *}$ & $.88^{* *}$ & $.37^{\star \star}$ & $.09^{*}$ & $.62^{\star *}$ \\
\hline Adaptabilidad & $.26^{* *}$ & $.34^{* *}$ & $.92^{* *}$ & -.01 & $.60^{* *}$ \\
\hline Manejo del estrés & $.09^{* *}$ & $.11^{* *}$ & $.09^{\star *}$ & $.90 * *$ & $.56^{\star *}$ \\
\hline CE total & $.68^{* *}$ & $.54^{* *}$ & $.63^{\star *}$ & $.41^{* *}$ & $.95^{\star *}$ \\
\hline Estado de A. G. & $.29 * *$ & $.38^{* *}$ & $.43^{* \star}$ & $.21^{\star *}$ & $.54^{\star *}$ \\
\hline
\end{tabular}

Nota: Intra = Intrapersonal; Inter = interpesonal; Adapt. = Adaptabilidad; estrés $=$ Manejo del estrés; Total $=$ Cociente emocional total; Estado de A.G. = Estado de ánimo general; $\mathrm{CE}$ total $=$ Cociente emocional total ${ }^{* *} \mathrm{p}<.01$

${ }^{*} \mathrm{p}<.05$

las otras escalas interpersonal, intrapersonal, adaptabilidad y manejo del estrés, y elevados para la escala de estado de ánimo general, mejorando la confiabilidad con la edad.

Cuando se considera la gestión, la consistencia interna también progresa con la edad, pero es más elevada para los colegios estatales. Este análisis también revela la homogeneidad de los ítemes en relación con el constructo medido por cada escala.

En el estudio peruano no se aprecian grandes diferencias por género cuando se hace referencia a la competencia emocional general y social; sin embargo, las diferencias son notorias por gestión, tal como se ilustra en las figuras 3 y 4 . 
Tabla 39

Correlaciones entre el BarON ICE: NA Forma completa y el I-CE de BarOn para adultos en estudiantes universitarios

\begin{tabular}{|c|c|c|c|c|c|c|}
\hline \multirow{2}{*}{$\begin{array}{l}\text { I-CE de BarOn } \\
\text { para adultos }\end{array}$} & \multicolumn{6}{|c|}{ BarOn ICE: NA - completa } \\
\hline & Intra. & Inter. & Adapt. & estrés & Total & ánimo \\
\hline \multicolumn{7}{|l|}{ Varones $(N=18)$} \\
\hline Intrapersonal & $.78^{\star \star}$ & .45 & $.78^{\star *}$ & $.64^{\star *}$ & $.83^{\star \star}$ & .28 \\
\hline Interpersonal & .27 & .35 & .30 & .17 & .36 & .43 \\
\hline Adaptab & $.80^{\star *}$ & $.47^{* *}$ & $.72^{\star \star}$ & $.56^{\star \star}$ & $.79^{\star \star}$ & .11 \\
\hline Manejo del estrés & $.72^{\star \star}$ & .46 & $.66^{\star \star}$ & .45 & $.72^{\star \star}$ & -.10 \\
\hline CE total & $.84^{\star *}$ & $.58^{\star *}$ & $.81^{* *}$ & $.60^{\star *}$ & $.89^{\star *}$ & .28 \\
\hline Estado de A. G. & .22 & .23 & .23 & .22 & .29 & .43 \\
\hline \multicolumn{7}{|l|}{ Mujeres $(N=59)$} \\
\hline Intrapersonal & $.52^{\star \star}$ & $.56^{\star \star}$ & $.56^{\star \star}$ & $.44^{\star *}$ & $.72^{\star \star}$ & $.44^{\star \star}$ \\
\hline Interp & .13 & .03 & .18 & $.28^{*}$ & .27 & $.43^{\star *}$ \\
\hline Adaptabil & $.48^{\star \star}$ & $.55^{\star \star}$ & $.57^{\star \star}$ & $.30^{*}$ & $.66^{\star \star}$ & $.50^{\star *}$ \\
\hline Manejo del estrés & $.34^{\star *}$ & $.39^{\star *}$ & $.41^{* *}$ & $.50^{\star *}$ & $.59^{\star *}$ & .22 \\
\hline CE Total & $.51^{\star *}$ & $.52^{\star *}$ & $.58^{\star *}$ & $.61^{* *}$ & $.79^{\star *}$ & $.59^{\star \star}$ \\
\hline Estado de A. G. & .11 & .10 & -.02 & $.57^{\star \star}$ & $.29^{\star}$ & $.27^{*}$ \\
\hline
\end{tabular}

Nota: Intra = Intrapersonal; Inter $=$ interpesonal; Adapt. = Adaptabilidad; estrés $=$ Manejo del estrés; Total $=$ Cociente emocional total; Estado de A.G. = Estado de ánimo general; $\mathrm{CE}$ total $=$ Cociente emocional total ${ }^{* *} p<.01$

${ }^{*} p<.05$

Tabla 41

Correlaciones entre el BarON ICE:

NA - Forma completa y el Inventario de Depresión de Reynolds para Adolescentes de un centro educativo estatal de Viña Alta

\begin{tabular}{ccccccc}
\hline \multirow{2}{*}{ Depresión } & \multicolumn{6}{c}{ BarOn ICE: NA - completa } \\
& Intra. & Inter. & Adapt. & estrés & Total & ánimo \\
\hline $\begin{array}{c}\text { Varones }(\mathrm{N}=36) \\
\text { PT Depresión }\end{array}$ & -.02 & -.11 & -.29 & .32 & -.05 & $-.36^{\star}$ \\
Mujeres $(\mathrm{N}=46)$ & & & & & & \\
PT Depresión & -.15 & -.28 & $-.42^{\star *}$ & .14 & -.26 & $-.70^{\star \star}$ \\
\hline
\end{tabular}

Nota: Intra = Intrapersonal; Inter $=$ interpesonal; Adapt. = Adaptabilidad estrés $=$ Manejo del estrés; Total $=$ Cociente emocional total $;$ PT $=$ Puntaje total de depresión

${ }^{* *} p<.01$

${ }^{*} p<.05$
Tabla 40

Correlaciones entre el BarON ICE: NA Forma completa y el I-CE de BarOn para adultos en estudiantes universitarios

\begin{tabular}{llllll}
\hline $\begin{array}{c}\text { I-CE de BarOn } \\
\text { para adultos }\end{array}$ & \multicolumn{5}{c}{ BarOn ICE: NA - abreviada } \\
& Intra. & Inter. & Adapt. & estrés & Total \\
\hline Varones $(\mathrm{N}=18)$ & & & & & \\
Intrapersonal & $.79^{* *}$ & .15 & $.69^{* *}$ & .45 & $.82^{* *}$ \\
Interpersonal & .27 & .41 & .11 & .10 & .36 \\
Adaptabilidad & $.80^{* *}$ & .19 & $.69^{* *}$ & .40 & $.81^{* *}$ \\
Manejo del estrés & $.72^{* *}$ & .11 & $.53^{*}$ & .37 & $.71^{* *}$ \\
CE total & $.84^{* *}$ & .36 & $.67^{* *}$ & .44 & $.90^{* *}$ \\
Estado de A. G. & .22 & $.58^{*}$ & .28 & .12 & .36 \\
& & & & & \\
Mujeres (N = 60) & & & & & $.76^{* *}$ \\
Intrapersonal & $.52^{* *}$ & $.40^{* *}$ & $.56^{* *}$ & $.38^{* *}$ & $.74^{* *}$ \\
Interpersonal & .13 & $.50^{* *}$ & .14 & .20 & $.28^{*}$ \\
Adaptabilidad & $.48^{* *}$ & $.33^{*}$ & $.44^{* *}$ & $.27^{*}$ & $.66^{* *}$ \\
Manejo del estrés & $.34^{* *}$ & $.27^{*}$ & $.33^{* *}$ & $.43^{* *}$ & $.56^{* *}$ \\
CE Total & $.51^{* *}$ & $.61^{* *}$ & $.48^{* *}$ & $.51^{* *}$ & $.80^{* *}$ \\
Estado de A. G. & .110 & $.47^{* *}$ & -.12 & $.48^{* *}$ & $.28^{*}$ \\
& & & & & \\
\hline
\end{tabular}

Nota: Intra = Intrapersonal; Inter = interpesonal; Adapt. = Adaptabilidad; estrés = Manejo del estrés; Total $=$ Cociente emocional total; Estado de A.G. = Estado de ánimo general; CE total = Cociente emocional total ${ }^{\star *} p<.01$

${ }^{*} \mathrm{p}<.05$
Correlaciones entre el BarON ICE:

NA - Forma abreviada y el Inventario de Depresión de Reynolds para Adolescentes de un centro educativo estatal de Viña Alta

\begin{tabular}{cccccc}
\hline Depresión & \multicolumn{5}{c}{ BarOn ICE: NA - abreviada } \\
& Intra. & Inter. & Adapt. & estrés & Total \\
\hline $\begin{array}{c}\text { Varones }(\mathrm{N}=36) \\
\text { PT Depresión }\end{array}$ & -.02 & .04 & -.31 & $.35^{\star}$ & .02 \\
Mujeres $(\mathrm{N}=46)$ & -.15 & -.11 & -.28 & .24 & -.10 \\
PT Depresión & & & & & \\
\hline
\end{tabular}

Nota: Intra = Intrapersonal; Inter = interpesonal; Adapt. = Adaptabilidad; estrés = Manejo del estrés; Total = Cociente emocional total; $\mathrm{PT}=$ Puntaje total de depresión

${ }^{*} p<.05$ 
Figura 3

Inteligencia emocional, grupos de edad y gestión

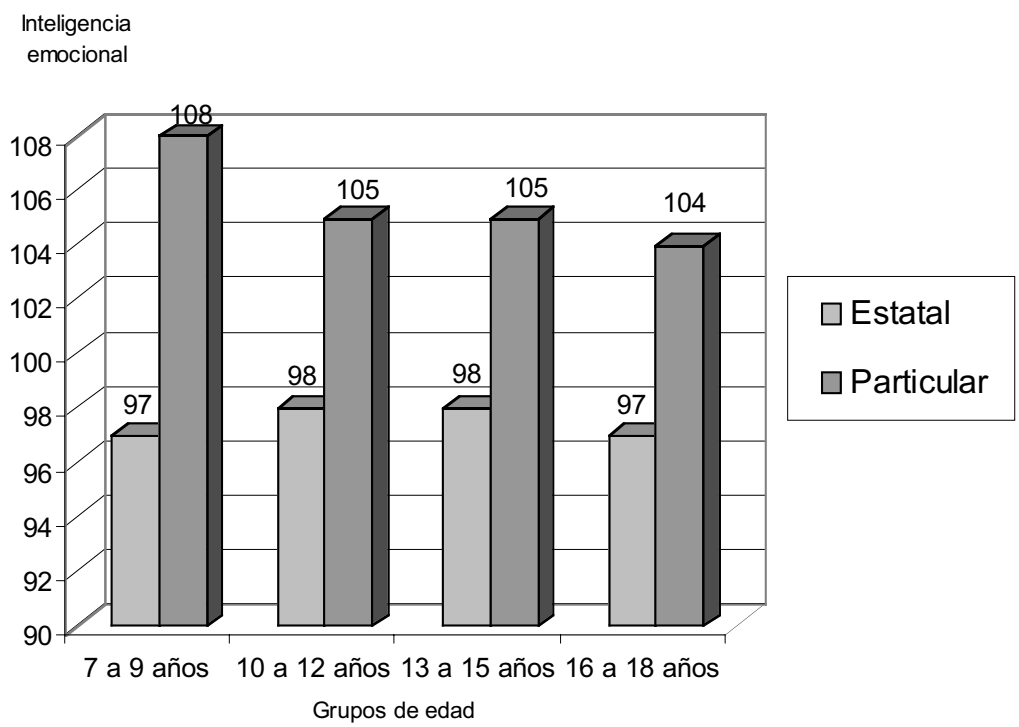

Figura 4

Inteligencia emocional, grupos de edad, sexo y gestión

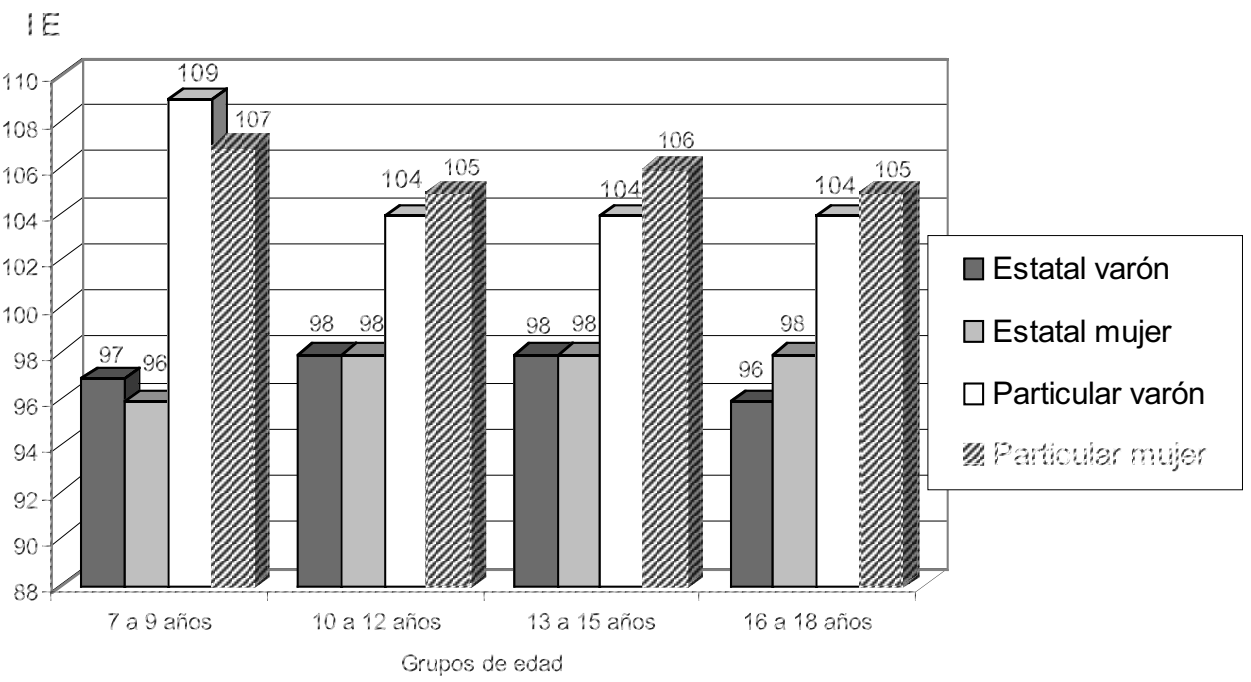


Cuando se examinan los efectos de la interacción edad y sexo, encontramos que los adolescentes a partir de los 13 años, tanto varones como mujeres, presentan interacciones sociales y habilidades de adaptación más bajas que los niños. En manejo del estrés los adolescentes mayores presentan una menor tolerancia y un menor control de impulsos, coincidiendo con características propias del desarrollo y la incertidumbre de lo que harán en el futuro, debido a que no tienen claro un proyecto de vida, pues la educación no los prepara para ello, tal como se aprecia en la figura 5. Esto difiere con los datos reportados en la muestra norteamericana, donde la inteligencia emocional se incrementa con la edad, tal como se señala en un estudio conducido por BarOn y Parker (2000).
En la interacción de las variables gestión y edad, el grupo de niños y adolescentes de colegios particulares denotan un mejor conocimiento de sí mismos, una mejor interacción social, mayor adaptabilidad, una imagen más positiva de sí mismos y una inteligencia emocional más elevada que los estatales, debido a que la experiencia emocional se encuentra influida por el contexto y es en gran medida dependiente del significado que le asignamos, incluyendo los roles que desempeñamos condicionados por el género, la edad y las diferencias de estatus socioeconómico y culturales.

La validez de un instrumento está destinada básicamente a demostrar cuán exitoso y eficiente es este en la medición de un concepto o un constructo que está diseñado para evaluar.

Figura 5

Inteligencia emocional y edades

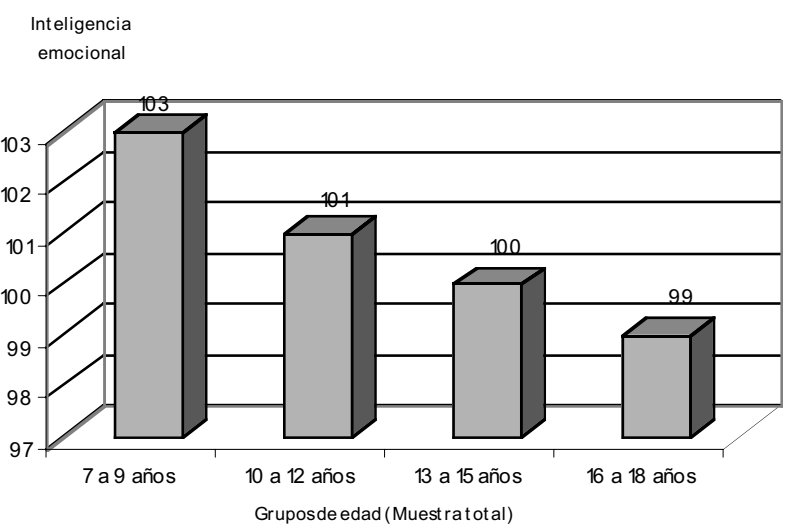


No existe un modo absoluto de conocer si un instrumento mide completamente un constructo, dado que este nunca puede ser perfectamente medido por cualquier medio. Sin embargo, se desea demostrar que existe un número suficiente de estudios que, utilizando diversas metodologías, presentan la evidencia con que el instrumento mide, de manera adecuada, el propósito para el que fue diseñado.

La validación del BarOn ICE: NA, formas completa y abreviada, se presenta en el manual original del inventario (BarOn \& Parker, 2000). Se estableció, en primer lugar, la estructura factorial de los 40 ítems de las escalas intrapersonal, interpersonal, manejo del estrés y adaptabilidad, mediante un análisis factorial exploratorio en una muestra normativa de niños y adolescentes de diferentes grupos raciales en los Estados Unidos de América $(\mathrm{N}=$ 9172). Se utilizó un análisis de componentes principales con una rotación Varimax. Los factores empíricos hallados correspondían cercanamente a las cuatro escalas del inventario que fueron desarrolladas para evaluar la inteligencia emocional. Casi los 40 ítems cargaban el mayor peso de modo moderado en su factor correspondiente y tenían muy bajos pesos en los otros tres factores. La forma abreviada del inventario presentó una solución similar.

Las intercorrelaciones de las diferentes escalas para las versiones tanto completa como abreviada de la versión norteamericana del inventario, presentan correlaciones desde bajas hasta moderadas, lo que brinda apoyo al carácter multidimensional del inventario, que revelaría que mide diferentes aspectos de la inteligencia emocional.

Las intercorrelaciones entre las escalas correspondientes del inventario de las formas completa y abreviada, muestran una alta congruencia. Por ejemplo, en la escala interpersonal de la versión completa, con la misma escala de la versión abreviada, tanto en varones como en mujeres, la correlación existente fue de .92 .

Así mismo, BarOn \& Parker (2000) informan en el manual técnico sobre otros estudios relativos a la validación del inventario con otras mediciones de la inteligencia emocional, de la personalidad y otros instrumentos que evalúan conductas problemáticas, y los resultados demuestran que las escalas del inventario de BarOn EQ-i: YV identifican las características centrales de la inteligencia emocional en niños.

En el caso de la muestra normativa peruana, la validación del BarOn ICE: NA se ha centralizado en dos asuntos importantes: a) la validez de constructo del inventario, y b) la multidimensionalidad de la diversas escalas. Aunque la validez de cualquier medida es un proceso continuo, se puede sostener que este inventario tiene suficiente validez de constructo, que garantiza su publicación y recomendación para uso clínico y educativo. 
La estructura factorial de los 40 ítems del ICE: NA, formas completa y abreviada de las escalas intrapersonal, interpersonal, manejo del estrés y adaptabilidad, se examinaron mediante un análisis factorial exploratorio con una rotación Varimax en la muestra normativa peruana de niños y adolescentes de Lima metropolitana $(\mathrm{N}=3374)$, y para las submuestras según sexo y gestión. Los cuatro factores empíricos que surgieron de este análisis corresponden a las cuatro escalas del BarOn ICE: NA que fueron desarrolladas para medir la inteligencia emocional, coincidiendo en gran medida los factores encontrados tanto en la muestra total peruana como en las submuestras según sexo y gestión con la solución factorial hallada en la investigación norteamericana; además, la mayoría de ítemes también conservan su ubicación dentro del factor respectivo.

Es interesante destacar que para las dos versiones del ICE: NA las soluciones factoriales son muy similares tanto para la muestra total como para las submuestras. El ordenamiento de las escalas según los pesos factoriales se da en el siguiente sentido: adaptabilidad, manejo del estrés interpersonal e intrapersonal, con excepción del grupo de mujeres que presentan una secuencia de mayor peso para el interpersonal, seguido de adaptabilidad, manejo del estrés e intrapersonal, siendo además semejantes las varianzas explicadas, lo cual sugiere factores comunes que en un análisis posterior podrían constituir un solo factor. Es interesante destacar cómo las mujeres, desde niñas, muestran más su habilidad para interactuar y adaptarse al medio social, lo que es enfatizado por el rol que la familia, la escuela y la comunidad les asignan y refuerzan.

En general, en la escala intrapersonal las cargas factoriales ofrecen los resultados más bajos, esto podría atribuirse a que tanto los niños como los adolescentes no desarrollan adecuadamente una autocomprensión de sus propias emociones, ya sea por factores de inmadurez o por la educación, que no favorece que se percaten de sus sentimientos y expresiones emocionales.

A diferencia de la versión norteamericana, se realizó un análisis factorial considerando el tipo de gestión, lo que sí mostró resultados diferentes dadas las diferencias socioeconómicas y culturales que caracterizan a los colegios estatales y privados. En los primeros, las cargas factoriales son mayores en la adaptabilidad y el manejo del estrés, en cambio en los privados ocurre lo contrario. Este hecho se puede explicar debido a que los niños y adolescentes que viven en realidades ambientales menos favorables e inestables se comportan de una manera pasiva frente a las circunstancias que no pueden modificar, experimentando una desesperanza aprendida, careciendo de posibilidades de elegir entre opciones, que los lleva a aceptar pasivamente las circunstancias. 
Otros análisis de la validez, como el de las intercorrelaciones de las diferentes escalas del inventario, brindan un soporte adicional a favor de la multidimensionalidad del instrumento, ya que las intercorrelaciones, aunque bajas y moderadas, son significativas.

Las correlaciones entre las escalas similares de las dos formas son muy elevadas, por ejemplo, la escala manejo del estrés de la forma completa con el manejo del estrés de la forma abreviada es de .89 , tanto para el grupo de varones como para el de mujeres. Lo que respalda la validez de ambas escalas y su uso indistinto.

Las correlaciones entre las diferentes escalas del Inventario de Niños y Adolescentes y las escalas correspondientes al Inventario de Adolescentes y Adultos fueron desde moderadas hasta altas en ambas formas. Asimismo, es interesante destacar que la correlación tanto de la forma completa como abreviada del Inventario de BarOn ICE: NA con el Inventario de Depresión de Reynolds revelan la validez divergente de la medición del constructo inteligencia emocional con el de depresión, siendo las correlaciones inversas y significativas. Así, por ejemplo, a mayor depresión menor adaptabilidad y a mayor depresión menor estado de ánimo general.

El presente trabajo, a diferencia del estudio norteamericano, no solo incluye validaciones considerando la edad y el sexo, sino también la gestión admi- nistrativa escolar, ya que los colegios públicos y privados evidencian las acentuadas diferencias económicas y sociales que existen en nuestra realidad y que pueden plantear diferentes modelos explicativos concernientes a la inteligencia emocional.

\section{REFERENCIAS}

BarOn, R. (1988). The development of a concept of psychological well-being. Disertación doctoral inédita. Grahamstown. Sudáfrica: Rhodes University.

BarOn, R. (1997a). Development of the Baron EQ-I: A measure of emotional and social intelligence. $105^{\text {th }}$ Annual Convention of the American Psychological Association in Chicago.

BarOn, R. (1997b). BarOn Emotional Quotient Inventory. Technical manual. Toronto: Multi-Health Systems Inc.

BarOn, R. \& Parker, J. (2000). EQi: YV BarOn Emotional Quotient Inventory: Youth version. Technical manual. Toronto: Multi-Health Systems Inc.

Beitchman, J. (1996). Feelings, attitudes and behaviors scale for children. Toronto: Multi-Health Systems Inc.

Booth-Butterfield, M. \& Booth-Butterfield, S. (1990). Conceptualizing affect as information in communication production. Human Communication Research, 16, 451-476.

Carpendale, J. (1997). An explication of Piaget's constructivism: Implications for social cognitive development. En: S. Hala (Ed.), The development of so- 
cial cognition. Hove, East Sussex, U.K.: Psychology Press, 35-64.

Davies, M., Stankov, L. \& Roberts, R. (1998). Emotional intelligence: In search of an elusive construct. Journal of Personality and Social Psychology, 75(4), 980-1015.

Escurra, M. \& Cols. (2000). Construcción de una prueba de inteligencia emocional. Revista de Investigación en Psicología, 3(1), 71-85.

Gardner, H. (1983). Frames of mind. New York: Basic Books.

Gardner, H., Kornhaber, M. y Krechevsky, M. (1993). Abordar el concepto de inteligencia. En: Gardner, H. (Ed.). Inteligencias múltiples: La teoría en la práctica. Barcelona: Paidós.

Goleman, D. (1996). Inteligencia emocional. Barcelona: Kairós.

Goleman, D. (1998). Working with emotional intelligence. New York: Bantam.

Greenberg, L. (1996). Conferencia impartida el 12 de setiembre del año 1996 en la Facultad de Psicología de la Universidad de Valencia, España.

Instituto Nacional de Estadística e Informática (1999). Encuesta Nacional de Hogares (Enaho). Lima: INEI.

Marina, J. (1993). Teoría de la inteligencia creadora. Barcelona: Anagrama.

Mayer, R. (1983). Pensamiento, resolución de problemas y cognición. Barcelona: Paidós.

Mayer, J. \& Salovey, P. (1988). Personality moderates the effects of affect on cognition. En: Forgas, J. \& Fiedler, K. (Eds.). Affect, cognition, and social behavior. Toronto: Hogrefe.
Mayer, J. \& Salovey, P. (1990). Emotional intelligence. Imagination, cognition and personality, 9(3), 185-211.

Mayer, J. \& Salovey, P. (1993). The intelligence of emotional intelligence. Intelligence, 17(4), 433-442.

Mayer, J. \& Salovey, P. (1997). What is emotional intelligence? En: Salovey, P. \& Sluyter, D. (Eds.). Emotional development, emotional literacy, and emotional intelligence. New York: Basic Books.

Mayer, J. \& Stevens, A. (1994). An emerging understanding of the reflective (meta) experience of mood. Journal of Research in Personality, 28, 35-373.

Mayer, J. \& Geher, G. (1996). Emotional intelligence and the identification of emotion, Intelligence, 22, 89-113.

Mayer, J., Caruso, D. \& Salovey, P. (1997). Emotional intelligence meets traditional standars for an intelligence. Manuscript submitted for publication.

Mayer, J.; Salovey, P. \& Caruso, D. (2000). Models of emotional intelligence. En: Stenberg, R. J. (ed.). Hand book of intelligence. New York: Cambridge.

Molero, C., Saíz, E. \& Esteban, C. (1998). Revisión histórica del concepto de inteligencia: una aproximación a la inteligencia emocional. Revista Latinoamericana de Psicología, 30(1), 11-30.

Nunnally, J. \& Bernstein, I. (1995). Teoría psicométrica. México: McGraw-Hill.

O’Sullivan, M. y Guilford, J. (1975). Six factors of behavioral cognition: Understanding other people. Journal of Educational Measurement, 12, 255-271.

Pallaza, R. \& BarOn, R. (1995). A study of the emotional intelligence of convicted criminals. Manuscrito no publicado. 
Saarni, C. (1997). Coping with aversive feelings. Motivation and Emotion, 21, 45-67.

Saarni, C. (1999). The development of emotional competence. Nueva York: Guilford.

Salovey, P. \& Mayer, J. (1989-90). Emotional intelligence. Imagination, Cognition and Personality, 9(3), 18-211.

Salovey, P., Hsee, C., \& Mayer, J. (1993). Emotional intelligence and the self-regulation of affect. En: Wegner, M. D. \& Pennebaker, J. W. (Eds.). Handbook of mental control. Englewood Cliffs, NJ: Prentice-Hall.

Salovey, P. \& Mayer, J. (1994). Some final thoughts about personality and intelligence. En: Sternberg, R. J. (Ed.). Personality and intelligence. Nueva York: Cambridge University Press.

Scarr, S. \& Carter-Salzman, L. (1989). Genética e inteligencia. En: Sternberg, R. J. (Ed.). Inteligencia humana. IV Evolución y desarrollo de la inteligencia. Barcelona: Paidós Ibérica.
Shutte, N. et al. (1998). Development and validation of measure of emotional intelligence. Personality and Individual Differences, 25, 167-177.

Spearman, C. (1927). The abilities of man. Nueva York: The Macmillan Co.

Spivack, G.; Platt, J. \& Shure, M. (1976). The problem solving approach to adjustment: A guide to research and intervention. San Francisco: Jossey-Bass.

StafSoft (1995). Statistica for Windows. Tulsa, OKlahoma: StatSoft.

Thorndike, R. (1936). Factor analysis of social and abstract intelligence. Journal of Educational Psychology, 27, 231-233.

Ugarriza, N. (2003). La evaluación de la inteligencia emocional a través del Inventario de BarOn (I-CE) en una muestra de Lima Metropolitana, 2. ${ }^{\text {a edición. }}$ Lima: Ediciones Libro Amigo.

Ugarriza, N. \& Pajares, L. (2004). Adaptación y estandarización del Inventario de Inteligencia Emocional de BarOn ICE: NA, en niños y adolescentes. Manual técnico. Lima: Edición de las autoras. 


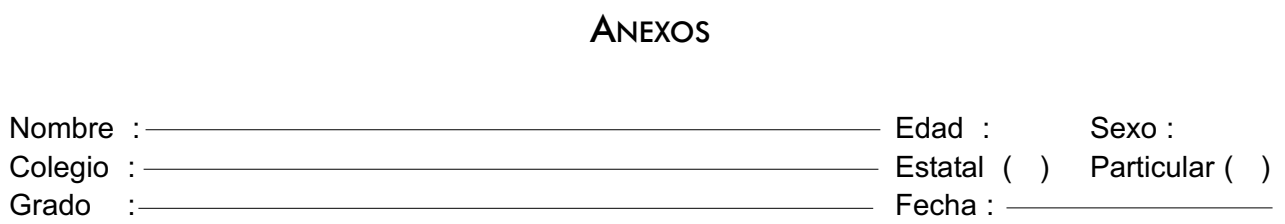

INVENTARIO EMOCIONAL BarOn ICE: NA - COMPLETA

Adaptado por

Nelly Ugarriza Chávez

Liz Pajares del Águila

Lee cada oración y elige la respuesta que mejor te describe, hay cuatro posibles respuestas:

1. Muy rara vez

2. Rara vez

3. A menudo

4. Muy a menudo

Dinos cómo te sientes, piensas o actúas LA MAYOR PARTE DEL TIEMPO EN LA MAYORÍA DE LUGARES. Elige una, y solo UNA respuesta para cada oración y coloca un ASPA sobre el número que corresponde a tu respuesta. Por ejemplo, si tu respuesta es "Rara vez", haz un ASPA sobre el número 2 en la misma línea de la oración. Esto no es un examen; no existen respuestas buenas o malas. Por favor haz un ASPA en la respuesta de cada oración.

\begin{tabular}{lcccc}
\hline & $\begin{array}{c}\text { Muy } \\
\text { rara vez }\end{array}$ & $\begin{array}{c}\text { Rara } \\
\text { vez }\end{array}$ & $\begin{array}{c}\text { A } \\
\text { menudo menudo }\end{array}$ & $\begin{array}{c}\text { Muy a } \\
\text { 1. Me gusta divertirme. }\end{array}$ \\
1. Soy muy bueno (a) para comprender cómo la & 1 & 2 & 3 & 4 \\
gente se siente. & & 2 & 3 & 4 \\
3. Puedo mantener la calma cuando estoy molesto. & 1 & 2 & 3 & 4 \\
4. Soy feliz. & 1 & 2 & 3 & 4 \\
5. Me importa lo que les sucede a las personas. & 1 & 2 & 3 & 4 \\
6. Me es difícil controlar mi cólera. & 1 & 2 & 3 & 4 \\
7. Es fácil decirle a la gente cómo me siento. & 1 & 2 & 3 & 4 \\
8. Me gustan todas las personas que conozco. & 1 & 2 & 3 & 4 \\
9. Me siento seguro (a) de mí mismo (a). & 1 & 2 & 3 & 4 \\
10. Sé cómo se sienten las personas. & 1 & 2 & 3 & 4 \\
11. Sé cómo mantenerme tranquilo (a). & 1 & 2 & 3 & 4 \\
12. Intento usar diferentes formas de responder las & 1 & 2 & 3 & 4 \\
preguntas difíciles. & & & & \\
13. Pienso que las cosas que hago salen bien. & 1 & 2 & 3 & 4 \\
14. Soy capaz de respetar a los demás. & 1 & 2 & 3 & 4 \\
15. Me molesto demasiado de cualquier cosa. & 1 & 2 & 3 & 4 \\
16. Es fácil para mí comprender las cosas nuevas. & 1 & 2 & 3 & 4 \\
17. Puedo hablar fácilmente sobre mis sentimientos. & 1 & 2 & 3 & 4 \\
18. Pienso bien de todas las personas. & 1 & 2 & 3 & 4 \\
19. Espero lo mejor. & 1 & 2 & 3 & 4 \\
20. Tener amigos es importante. & 1 & 2 & 3 & 4
\end{tabular}




\begin{tabular}{|c|c|c|c|c|}
\hline & $\begin{array}{l}\text { Muy } \\
\text { rara vez }\end{array}$ & $\begin{array}{c}\text { Rara } \\
\text { vez }\end{array}$ & $\begin{array}{c}\text { A } \\
\text { menudo }\end{array}$ & $\begin{array}{l}\text { Muy a } \\
\text { menudo }\end{array}$ \\
\hline 21. Peleo con la gente. & 1 & 2 & 3 & 4 \\
\hline 22. Puedo comprender preguntas difíciles. & 1 & 2 & 3 & 4 \\
\hline 23. Me agrada sonreír. & 1 & 2 & 3 & 4 \\
\hline 24. Intento no herir los sentimientos de las personas. & 1 & 2 & 3 & 4 \\
\hline $\begin{array}{l}\text { 25. No me doy por vencido (a) ante un problema hasta } \\
\text { que lo resuelvo. }\end{array}$ & 1 & 2 & 3 & 4 \\
\hline 26. Tengo mal genio. & 1 & 2 & 3 & 4 \\
\hline 27. Nada me molesta. & 1 & 2 & 3 & 4 \\
\hline 28. Es difícil hablar sobre mis sentimientos más íntimos. & 1 & 2 & 3 & 4 \\
\hline 29. Sé que las cosas saldrán bien. & 1 & 2 & 3 & 4 \\
\hline 30. Puedo dar buenas respuestas a preguntas difíciles. & 1 & 2 & 3 & 4 \\
\hline 31. Puedo fácilmente describir mis sentimientos. & 1 & 2 & 3 & 4 \\
\hline 32. Sé cómo divertirme. & 1 & 2 & 3 & 4 \\
\hline 33. Debo decir siempre la verdad. & 1 & 2 & 3 & 4 \\
\hline $\begin{array}{l}\text { 34. Puedo tener muchas maneras de responder una } \\
\text { pregunta difícil, cuando yo quiero. }\end{array}$ & 1 & 2 & 3 & 4 \\
\hline 35. Me molesto fácilmente. & 1 & 2 & 3 & 4 \\
\hline 36. Me agrada hacer cosas para los demás. & 1 & 2 & 3 & 4 \\
\hline 37. No me siento muy feliz. & 1 & 2 & 3 & 4 \\
\hline $\begin{array}{l}\text { 38. Puedo usar fácilmente diferentes modos de resolver } \\
\text { los problemas. }\end{array}$ & 1 & 2 & 3 & 4 \\
\hline 39. Demoro en molestarme. & 1 & 2 & 3 & 4 \\
\hline 40. Me siento bien conmigo mismo (a). & 1 & 2 & 3 & 4 \\
\hline 41. Hago amigos fácilmente. & 1 & 2 & 3 & 4 \\
\hline 42. Pienso que soy el (la) mejor en todo lo que hago. & 1 & 2 & 3 & 4 \\
\hline 43. Para mí es fácil decirle a las personas cómo me siento. & 1 & 2 & 3 & 4 \\
\hline $\begin{array}{l}\text { 44. Cuando respondo preguntas difíciles trato de pensar en } \\
\text { muchas soluciones. }\end{array}$ & 1 & 2 & 3 & 4 \\
\hline $\begin{array}{l}\text { 45. Me siento mal cuando las personas son heridas en sus } \\
\text { sentimientos. }\end{array}$ & 1 & 2 & 3 & 4 \\
\hline $\begin{array}{l}\text { 46. Cuando estoy molesto (a) con alguien, me siento } \\
\text { molesto (a) por mucho tiempo. }\end{array}$ & 1 & 2 & 3 & 4 \\
\hline 47. Me siento feliz con la clase de persona que soy. & 1 & 2 & 3 & 4 \\
\hline 48. Soy bueno (a) resolviendo problemas. & 1 & 2 & 3 & 4 \\
\hline 49. Para mí es difícil esperar mi turno. & 1 & 2 & 3 & 4 \\
\hline 50. Me divierte las cosas que hago. & 1 & 2 & 3 & 4 \\
\hline 51. Me agradan mis amigos. & 1 & 2 & 3 & 4 \\
\hline 52. No tengo días malos. & 1 & 2 & 3 & 4 \\
\hline 53. Me es difícil decirle a los demás mis sentimientos. & 1 & 2 & 3 & 4 \\
\hline 54. Me disgusto fácilmente. & 1 & 2 & 3 & 4 \\
\hline 55. Puedo darme cuenta cuando mi amigo se siente triste. & 1 & 2 & 3 & 4 \\
\hline 56. Me gusta mi cuerpo. & 1 & 2 & 3 & 4 \\
\hline 57. Aun cuando las cosas sean difíciles, no me doy por vencido & 1 & 2 & 3 & 4 \\
\hline 58. Cuando me molesto actúo sin pensar. & 1 & 2 & 3 & 4 \\
\hline 59. Sé cuándo la gente está molesta aun cuando no dicen nada & 1 & 2 & 3 & 4 \\
\hline 60. Me gusta la forma como me veo. & 1 & 2 & 3 & 4 \\
\hline
\end{tabular}


Nombre :

Edad :

Sexo :

Colegio :

Estatal ( ) Particular ( )

Grado

Fecha :

\section{INVENTARIO EMOCIONAL BarOn ICE: NA - COMPLETA \\ Adaptado por \\ Nelly Ugarriza Chávez \\ Liz Pajares del Águila}

Lee cada oración y elige la respuesta que mejor te describe, hay cuatro posibles respuestas:

1. Muy rara vez

2. Rara vez

3. A menudo

4. Muy a menudo

Dinos cómo te sientes, piensas o actúas LA MAYOR PARTE DEL TIEMPO EN LA MAYORÍA DE LUGARES. Elige una, y solo UNA respuesta para cada oración y coloca un ASPA sobre el número que corresponde a tu respuesta. Por ejemplo, si tu respuesta es "Rara vez", haz un ASPA sobre el número 2 en la misma línea de la oración. Esto no es un examen; no existen respuestas buenas o malas. Por favor haz un ASPA en la respuesta de cada oración.

\begin{tabular}{cccc}
\hline Muy & Rara & A & Muy a \\
rara vez & vez & menudo menudo \\
\hline
\end{tabular}

1. Me importa lo que les sucede a las personas.

2. Es fácil decirle a la gente cómo me siento.

3. Me gustan todas las personas que conozco.

4. Soy capaz de respetar a los demás.

5. Me molesto demasiado de cualquier cosa.

6. Puedo hablar fácilmente sobre mis sentimientos.

7. Pienso bien de todas las personas.

8. Peleo con la gente.

9. Tengo mal genio.

10. Puedo comprender preguntas difíciles.

11. Nada me molesta.

12. Es difícil hablar sobre mis sentimientos más íntimos.

13. Puedo dar buenas respuestas a preguntas difíciles.

14. Puedo fácilmente describir mis sentimientos.

15. Debo decir siempre la verdad.

16. Puedo tener muchas maneras de responder una pregunta difícil, cuando yo quiero.

17. Me molesto fácilmente.

18. Me agrada hacer cosas para los demás.

19. Puedo usar fácilmente diferentes modos de resolver los problemas.

$\begin{array}{llll}1 & 2 & 3 & 4 \\ 1 & 2 & 3 & 4 \\ 1 & 2 & 3 & 4 \\ 1 & 2 & 3 & 4 \\ 1 & 2 & 3 & 4 \\ 1 & 2 & 3 & 4 \\ 1 & 2 & 3 & 4 \\ 1 & 2 & 3 & 4 \\ 1 & 2 & 3 & 4 \\ 1 & 2 & 3 & 4 \\ 1 & 2 & 3 & 4 \\ 1 & 2 & 3 & 4 \\ 1 & 2 & 3 & 4 \\ 1 & 2 & 3 & 4 \\ 1 & 2 & 3 & 4 \\ 1 & 2 & 3 & 4 \\ 1 & 2 & 3 & 4 \\ 1 & 2 & 3 & 4 \\ 1 & 2 & 3 & 4\end{array}$




$\begin{array}{ccc}\text { Muy } & \text { Rara } & \text { A } \quad \text { Muy a } \\ \text { rara vez } & \text { vez } & \text { menudo menudo }\end{array}$

20. Pienso que soy el (la) mejor en todo lo que hago.

21. Para mí es fácil decirle a las personas cómo me siento.

$\begin{array}{llll}1 & 2 & 3 & 4\end{array}$

22. Cuando respondo preguntas difíciles trato de pensar en muchas soluciones.

$\begin{array}{llll}1 & 2 & 3 & 4\end{array}$

23. Me siento mal cuando las personas son heridas en sus sentimientos.

24. Soy bueno (a) resolviendo problemas.

25. No tengo días malos.

26. Me es difícil decirle a los demás mis sentimientos.

27. Me disgusto fácilmente.

28. Puedo darme cuenta cuando mi amigo se siente triste.

29. Cuando me molesto actúo sin pensar.

30. Sé cuándo la gente está molesta aun cuando no dicen nada

$\begin{array}{lll}2 & 3 & 4\end{array}$

\begin{tabular}{lll}
2 & 3 & 4 \\
2 & 3 & 4 \\
2 & 3 & 4 \\
2 & 3 & 4 \\
2 & 3 & 4 \\
2 & 3 & 4 \\
2 & 3 & 4 \\
2 & 3 & 4 \\
\hline
\end{tabular}

